\title{
Pro-resolving lipid mediators (SPMs) and their actions in regulating miRNA in novel resolution circuits in inflammation
}

\section{Antonio Recchiuti ${ }^{\dagger}$ and Charles N. Serhan*}

Center for Experimental Therapeutics and Reperfusion Injury, Department of Anesthesiology, Perioperative and Pain Medicine, Brigham and Women's Hospital, Harvard Medical School, Harvard Institutes of Medicine, Boston, MA, USA

\section{Edited by:}

Janos G. Filep, University of

Montreal, Canada

\section{Reviewed by:}

Egle Solito, Queen Mary University

London, UK

Paola Allavena, Clinical Institute

Humanitas, Italy

*Correspondence:

Charles N. Serhan, Center for Experimental Therapeutics and

Reperfusion Injury, Brigham and

Women's Hospital, 77 Avenue Louis

Pasteur, Harvard Institutes of

Medicine 829, Boston, MA 02115,

USA.

e-mail: cnserhan@zeus.bwh.

harvard.edu

\section{${ }^{\dagger}$ Present address:}

Antonio Recchiuti, Department of Biomedical Sciences "G. d'Annunzio" University of Chieti and Center of Excellence on Aging (CeSI) "G.

d'Annunzio" University Foundation, Chieti, Italy.
Unresolved inflammation is associated with several widely occurring diseases such as arthritis, periodontal diseases, cancer, and atherosclerosis. Endogenous mechanisms that curtail excessive inflammation and prompt its timely resolution are of considerable interest. In recent years, previously unrecognized chemical mediators derived from polyunsaturated fatty acids were identified that control the acute inflammatory response by activating local resolution programs. Among these are the so-called specialized pro-resolving lipid mediators (SPMs) that include lipoxins (LX), resolvins (Rv), protectins (PD), and maresins (MaR), because they are enzymatically biosynthesized during resolution of self-limited inflammation. They each possess distinct chemical structures and regulate cellular pathways by their ability to activate pro-resolving G-protein coupled receptors (GPCRs) in a stereospecific manner. For instance, RvD1 controls several miRNAs of interest in self-limited acute inflammation that counter-regulate the mediators and proteins that are involved in inflammation. Here, we overview some of the biosynthesis and mechanisms of SPM actions with focus on the recently reported miR involved in their pro-resolving responses that underscore their beneficial actions in the regulation of acute inflammation and its timely resolution. The elucidation of these mechanisms operating in vivo to keep acute inflammation within physiologic boundaries as well as stimulate resolution have opened resolution pharmacology and many new opportunities to target inflammation-related human pathologies via activating resolution mechanisms.

Keywords: resolution, resolvin, protectin, n-3 PUFA, lipoxin

\section{ACUTE INFLAMMATION: A PROTECTIVE HOST RESPONSE THAT CAN TURN HARMFUL}

Acute inflammation is a defensive physiological response occurring in vascularized tissues to protect the host against injuries (Majno and Joris, 1996). This formidable ally manifests its important role, for instance, in the early phase after a microbial infection, when it fights against invading pathogens before the adaptive immune system is engaged (Abbas et al., 2011). The characteristic "cardinal signs" of inflammation, described by the Roman physician Celsus in the first century, rubor (redness), tumor (swelling), calor (heat), and dolor (pain), are the macroscopic manifestation of changes that occur at molecular and cellular levels in inflamed tissues. Tissue edema is one of the earliest events in the acute inflammatory response that arises from increased vascular permeability of the microvasculature (Figure 1). Leukocytes are then recruited at sites of inflammation and traverse postcapillary venules. Polymorphonuclear neutrophils (PMN) are among the first leukocyte responders that accumulate in the inflamed site. As they are the first line of defense of the innate immune system, these cells kill pathogens by engulfing them via phagocytosis and release of microbicidal proteins stored in their intracellular granules and reactive oxygen species into phagolysosomal vacuoles to kill invaders (Majno and Joris, 1996). Next, in experimental acute inflammation, mononuclear cells enter the inflammatory site. They can differentiate into macrophages (MФs) and clear microbes, cellular debris, and apoptotic PMN by phagocytosis in a non-phlogistic process termed efferocytosis (Honn et al., 1989; Gordon, 2007; Serhan et al., 2007).

Ultimately, the clearance and efflux of phagocytes allow for resolution of the tissue and the return to homeostasis, namely catabasis (Figure 1). In order to maintain a healthy status, both the initiation of acute inflammation and its resolution must be efficient. Notably, it is not how often or how extensive an acute inflammatory reaction starts, but how effectively and quickly it resolves that determines whether the battle of inflammation is detrimental or the ideal favorable outcome for the host. Indeed, uncontrolled or unresolved inflammation is now recognized as a major driver of human pathologies, including arthritis, asthma, cancers, and cardiovascular diseases (Serhan, 2004; Serhan and Savill, 2005; Nathan and Ding, 2010). Given the high occurrence of these and many other diseases, understanding how acute inflammation resolves is of wide interest.

This review focuses on the specialized pro-resolving mediators (SPM) that are biosynthesized from essential polyunsaturated 


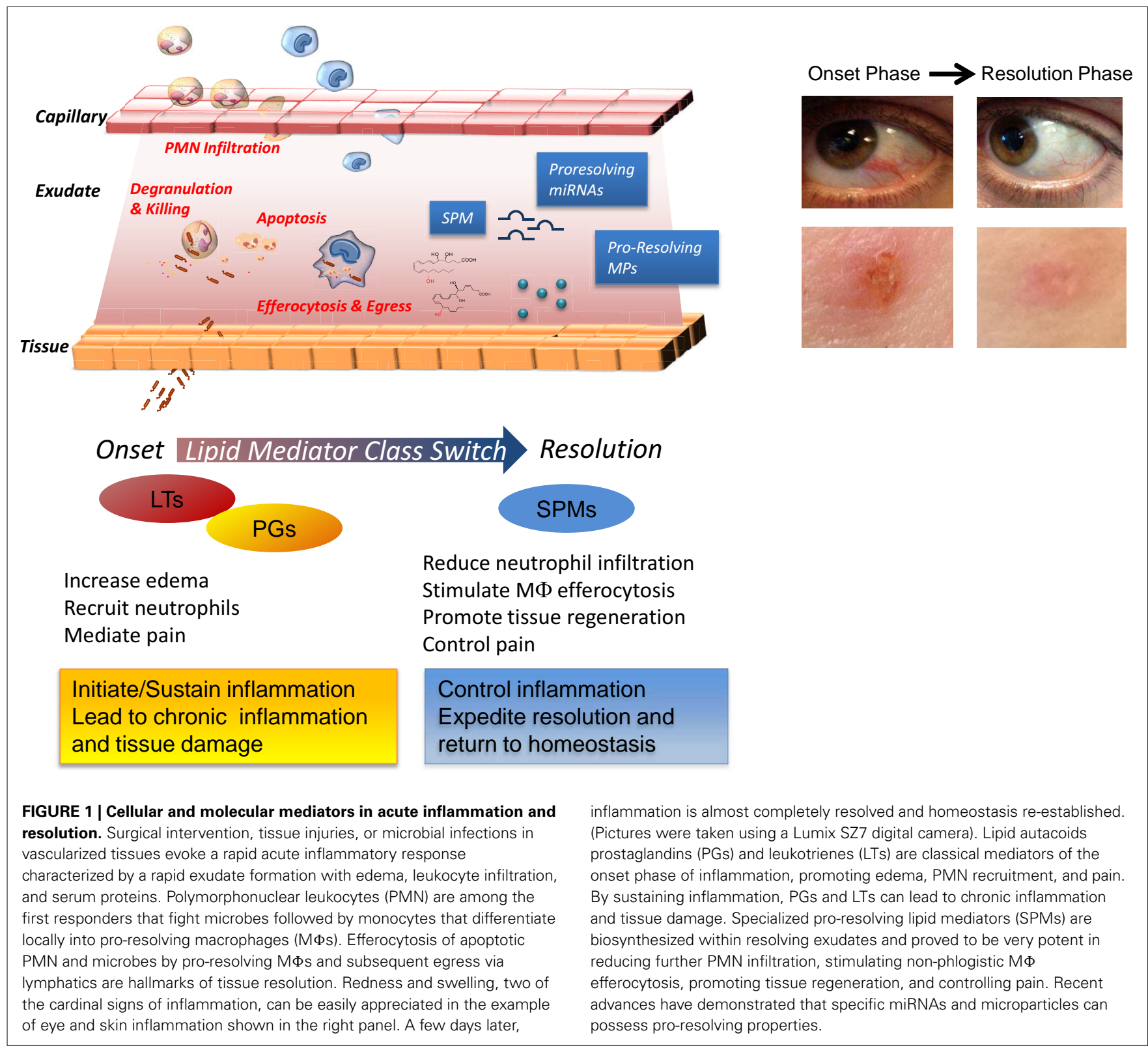

fatty acids (PUFAs), arachidonic acid (AA), eicosapentaenoic acid (EPA), and docosahexaenoic acid (DHA), namely lipoxins (LX), resolvins ( $\mathrm{Rv})$, protectins (PD), and maresins (MaR) and on their biosynthetic pathways, receptors, and miRNAs that act to control self-limited inflammation and promote its timely resolution. For readers interested in the biosynthesis of $\mathrm{Rv}$ and $\mathrm{PD}$, this subject was recently reviewed in detail in Bannenberg and Serhan (2010), and the confirmation and total organic synthesis in Serhan and Petasis (2011).

\section{RESOLUTION IS AN ACTIVE PROCESS CONTROLLED BY SPM:} SELF-LIMITED EXPERIMENTAL SYSTEM

At the histological level, resolution was well described by pathologists for more than 100 years as the time when the neutrophils that infiltrated the inflamed tissue sites leave or are lost from the site (Majno and Joris, 1996). Traditionally, resolution was thought to be a passive process, simply due to the attenuation/dissipation of chemotactic and pro-inflammatory signals. Our results (Serhan et al., 2000a; Levy et al., 2001), followed by those from many others worldwide (reviewed in a consensus report in Serhan et al., 2007) demonstrated that resolution is instead an active process orchestrated by special novel chemical mediators that turn on biochemical and cellular pathways to enable the return to homeostasis.

Lipid mediators (LM) from PUFA play essential roles in distinct phases of acute inflammation, with prostaglandins (PGs; Flower, 2006; Samuelsson, 2012) and cysteinyl leukotrienes (cysLTs) promoting early increase in vascular permeability and leukotriene (LT) $\mathrm{B}_{4}$ acting as a potent leukocyte chemoattractant (Samuelsson, 1983). Prostaglandins also contribute to fever and pain 
(von Euler, 1973). Chronic inflammation is widely viewed as an excess of pro-inflammatory mediators (Figure 1; Nathan and Ding, 2010). Results from our laboratory first demonstrated that the resolution phase is characterized by the active biosynthesis of specific LM that operate as "resolution agonists" to a) keep inflammation within physiological boundaries and b) expedite the complete return to homeostasis (Figure 1). The identification of this new array of LM was achieved using self-limited or naturally resolving acute inflammation models in vivo and a systems approach (Serhan et al., 2000a, 2002). The pharmacologic impact of the $\mathrm{Rv}$ and $\mathrm{PD}$ was reviewed in (Serhan and Chiang, 2008). This new array of LM is now recognized as a genus of SPM (Serhan and Chiang, 2008) that have two broad functions and are anti-inflammatory and pro-resolving via stimulating multi-level actions. Accruing evidence indicates that failure or disruption of the endogenous pro-resolution pathways governed by SPM can be detrimental and underlie some of the mechanisms of chronic inflammatory diseases (Gilroy et al., 1999; Karp et al., 2004; Schwab et al., 2007; Chan and Moore, 2010). SPM exert their potent dual anti-inflammatory and pro-resolving activities in the low nano- to microgram dose range when added back into experimental inflammatory disease models (Serhan and Chiang, 2008) and provide biotemplates for the design of novel therapeutics currently in clinical trials (see http://Clinicaltrials.Gov Identifier: NCT00799552). Therefore, harnessing these SPM may provide fascinating opportunities in the new and uncharted terrain of resolution pharmacology, with a substantial shift from a depletion pharmacology (i.e., via inhibitors, blockers, antagonists) toward a new approach based on resolution agonists that activate endogenous protective and clearance mechanisms.

Additional chemical mediators are operative in inflamed tissues to switch off leukocyte infiltration and restore their physiological functions. Among these are several cytokines (e.g., TGF $\beta$, IL-10) that accumulate in resolving exudates (Bannenberg et al., 2005); glucocorticoids and the glucocorticoid-induced annexin-1 protein, which tune the inflammatory response and bring about homeostasis (for a recent review see (Perretti and Dalli, 2009)); and the transcription factor NF- $\mathrm{B}$, which also carries some anti-inflammatory properties (Lawrence et al., 2001). Moreover, inducing PMN apoptosis as well as lymphoid cells while stimulating their prompt removal by $\mathrm{M} \Phi$ s also can promote resolution (Honn et al., 1989; Ariel et al., 2006). Recent results indicate that small inhibitors of cyclin-dependent kinases fulfill this goal (Leitch et al., 2012) as do annexin-1 peptides (Perretti and Dalli, 2009). Therefore, the resolution process can be pharmacologically targeted.

Importantly, resolution is not synonymous with endogenous anti-inflammation. This is because, in order to be considered a "pro-resolver," a chemical and/or molecular entity, in addition to serving as a "stop signal" for neutrophil trafficking and other cardinal signs of inflammation (e.g., swelling, pain), must also stimulate efferocytosis by $M \Phi$, favor the antibacterial activities, and promote tissue repair and regeneration to achieve homeostasis. Along these lines, $\mathrm{PGE}_{2}$ can have anti-inflammatory properties in certain settings via stimulation of cAMP, but is not acting as pro-resolver since it does not enhance the uptake and clearance of apoptotic cells by MФs (Kunkel et al., 1981). Also, although cyclooxygenase (COX) inhibitors as well as certain lipoxygenase (LO) inhibitors reduce some of the cellular events of the inflammatory reaction (e.g., edema formation, PMN recruitment, and pain), they dramatically impact the endogenous pro-resolution circuits and may delay or even derange this ideal outcome of acute inflammation and thus are "resolution toxic" (Gilroy et al., 1999; Schwab et al., 2007). In contrast, aspirin and glucocorticoids work synergistically with endogenous pro-resolution pathways (Perretti et al., 2002).

Complete resolution also requires the clearance of the remnants of damaged tissues and activated or apopotic cells, so-called microparticles (MPs). Originally viewed merely as empty vesicles, MPs are now recognized as "specialized shuttles" used by the organism to transfer bioactive molecules from cell to cell. Their role in inflammation and resolution is now being appreciated. Recently, the anti-inflammatory properties of a PMN-derived sub-population of MPs were uncovered, where they appear to signal to activate resolution mechanisms (Gasser and Schifferli, 2004; Dalli et al., 2008; Norling et al., 2011). Mimicking this new endogenous mechanism in resolution, novel human PMNderived nanoparticles containing AT-RvD1 or a $\mathrm{LXA}_{4}$ stable ana$\log$, termed humanized pro-resolving nanomedicines, were prepared. These SPM-enriched nanohumanized particles possessed beneficial bioactivities in reducing acute inflammation in vivo, expediting resolution, and promoting wound healing (Norling et al., 2011). Hence, NPs can serve as mimetics of endogenous pro-resolution pathways (Figure 1).

Active resolution includes gene expression regulation of several soluble chemical mediators (e.g., cytokines, chemokines), receptors (e.g., Toll-like receptors), as well as transcription factors. An emerging line of investigation indicates that many genes are under tight control of miRNAs, short non-coding RNA molecules that act as translational repressors of mRNA transcripts (Bartel, 2009). They are involved in many physiological and pathological processes, including cell development, cancer (Iorio and Croce, 2009), and inflammation (Sheedy and O'Neill, 2008; Alam and O'Neill, 2011; O'Neill et al., 2011). Our recent results uncovered roles of miRNAs in self-limited inflammation and in the resolution phase, specifically, RvD1-G-protein coupled receptor-dependent gene networks in resolution of acute inflammation as part of the endogenous circuitry that controls this active process (Recchiuti et al., 2011; Krishnamoorthy et al., 2012).

\section{IDENTIFYING SPM IN RESOLUTION}

An unbiased systems approach was taken to identify the endogenous SPM and decode their mechanisms of action in resolution. For this, the murine dorsal air pouch and self-limited acute inflammation was ideal because it permitted isolation of contained inflammatory exudates (Serhan et al., 2000a, 2002) and also enabled direct LM lipidomics of bioactive products, as well as their inactive precursors and further metabolites, proteomics, and analyses of cellular composition of the resolving exudate; namely the natural means by which inflammation returns to resolution and homeostasis. With this systems approach it was also possible to establish the local and temporal dissociation of LM biosynthesis (Bannenberg et al., 2005). For example, upon initiation 
of inflammation with TNF- $\alpha$, there was a typical acute-phase response characterized by rapid $\mathrm{PMN}$ infiltration preceded by local generation of both PGs and LTs. Unexpectedly, the eicosanoids undergo what was termed earlier a "class switch" and the profiles of LM made within this milieu switched with time (Levy et al., 2001). Indeed, the potent chemoattractants LT were deactivated and 15-LO required for LX and Rv production was transcriptionally activated (Levy et al., 2001). Notably, the omega-3 essential fatty acids DHA and EPA are precursors of Rv, PD, and MaR, are rapidly carried into the exudates via plasma edema and are then made available for conversion for the congregated exudate cells (Kasuga et al., 2008). Of interest, this LM class switching is driven in part by COX-derived $\mathrm{PGE}_{2}$ and $\mathrm{D}_{2}$, via transcriptional regulation of enzymes involved in LX biosynthesis (Levy et al., 2001). Hence, the concept that "alpha signals omega," namely the beginning signals the end in inflammation, was introduced by Sir John Savill and one of us to emphasize this finding (Serhan and Savill, 2005) to note that at time zero mediators are biosynthesized that signal to limit PMN influx and terminate the contained acute inflammatory response.

\section{WHAT IS A LIPID MEDIATOR?}

To qualify as a LM, a product must be stereoselective in its actions and be produced in amounts that are commensurate with its potency and range of action (Serhan et al., 1996). Along this line, LX, Rv, and PD are present in human serum in $\mathrm{pM}$ to $\mathrm{nM}$ amount (e.g., $\mathrm{LXA}_{4}, \sim 1.4 \mathrm{nM}$; RvD1, $\sim 50 \mathrm{pM}$; RvE1, $0.5 \mathrm{nM}$; values from the Serum Metabolome Project; Psychogios et al., 2011; see also Oh et al., 2011 for RvE1 and Oh et al., 2012 for RvE2 values) in human peripheral blood samples from healthy donors. LM lipidomics using liquid chromatography-tandem mass spectrometry (LC-MS/MS) coupled with informatics permit profiling of closely related compounds and identification of new molecules. Retrograde synthesis, both biogenic and total organic, allows the complete elucidation of chemical structure, stereochemistry, and physical properties, along with the recapitulation of the in vivo biosynthetic pathway (for examples see Sun et al., 2007; Serhan et al., 2009). The matching/identification of LM is usually carried out with at least two different instruments and/or mobile phase solvent systems and the criteria to identify a known LM are the following: (a) LC retention time should match by coelution with the LM authentic standard; (b) UV chromophore should match the synthetic and authentic LM (i.e., $\lambda_{\max }$ and band shape); as well as (c) $\geq 6$ diagnostic ions of tandem MS/MS spectrum (Figure 2). Also, the LC-MS/MS fragmentation mechanisms for the Rv and PD D1 and related DHA-derived products have been studied using deuterium-labeled compounds that facilitated their identification in vivo (Hong et al., 2007).

\section{LIPOXINS}

Lipoxin $\mathrm{A}_{4}$ and $\mathrm{B}_{4}$ were the first anti-inflammatory LM recognized to possess pro-resolving actions (Serhan et al., 1984a,b; Maddox et al., 1997; Takano et al., 1998; Godson et al., 2000). Although LXs were first isolated and identified in the 1980s in the Samuelsson laboratory (Serhan et al., 1984a), their potent bioactions were uncovered some years later with the identification of the aspirin-triggered LX (ATL; Claria and Serhan, 1995) and the design of ATL stable analogs (Serhan et al., 1995; vide infra), when it became clear that they act as "braking signals" of further PMN infiltration (Takano et al., 1998) and as potent stimuli for the non-phlogistic recruitment of monocytes (Maddox et al., 1997) and $M \Phi$ efferocytosis (Godson et al., 2000; recently reviewed in Serhan, 2005; Spite and Serhan, 2011). LXs are lipoxygenase interaction products derived from the enzymatic conversion of AA via transcellular biosynthesis during cell-cell interactions occurring during inflammation (Samuelsson et al., 1987). In humans, sequential oxygenation of AA by 15-LO and 5-LO, followed by enzymatic hydrolysis, leads to the biosynthesis of $\mathrm{LXA}_{4}$ and $\mathrm{B}_{4}$ in mucosal tissues, such as airways, gastrointestinal tract, and oral cavity (Edenius et al., 1990; Levy et al., 1993; Gronert et al., 1998; Figure 3 and reviewed in Romano (2010). Blood vessels represent a second site for LX biosynthesis, with the conversion of 5-LOderived $\mathrm{LTA}_{4}$ into $\mathrm{LXA}_{4}$ and $\mathrm{B}_{4}$ by 12 -LO in platelets (Serhan and Sheppard, 1990; Romano and Serhan, 1992; Romano, 2010).

\section{ATL: THE FIRST ASPIRIN-TRIGGERED MEDIATORS}

A third LX synthetic pathway is initiated by aspirin, the wellknown derivative of salicylates, by acetylation of COX-2. This covalent modification shifts the enzyme activity from endoperoxidase to lipoxygenase-like, and COX-2 converts AA into 15R-HETE, which is a substrate of leukocyte 5-LO for the biosynthesis of $15 \mathrm{R}$ epi-LXA 4 and $\mathrm{B}_{4}$ (Claria and Serhan, 1995). Hence, among the non-steroidal anti-inflammatory drugs (NSAID), aspirin has the unique capability to "jump start" resolution by its ability to trigger endogenous biosynthesis of so-called "aspirin-triggered" LX (Figure 3) Notably, ATL produced in vivo in human subjects taking aspirin (Chiang et al., 2004) proved to mediate the local antiinflammatory actions of low-dose aspirin in healthy individuals (Morris et al., 2009).

\section{SPM BIOSYNTHESIZED FROM OMEGA-3 POLYUNSATURATED FATTY ACIDS: LOCAL MEDIATORS}

The essential roles of omega-3 PUFA in health were evident in 1929 (Burr and Burr, 1929), and $\omega-3$, also known as n-3 PUFA EPA and DHA, have beneficial effects in human diseases including potential antithrombotic, immunoregulatory, and anti-inflammatory properties (Iigo et al., 1997; De Caterina, 2011). Also, the Gruppo Italiano per lo Studio della Sopravvivenza nell'Infarto MiocardicoPrevenzione trial evaluated the effects of $\omega$-3 PUFA supplementation with $>11,000$ patients surviving myocardial infarction taking $>1$ g of $\omega$-3 PUFA daily along with recommended preventive treatments including aspirin, and reported a significant benefit with a decrease in cardiovascular death (GISSI-Prevenzione Investigators, 1999). It is believed that the actions of the major lipid of fish oil EPA (C20:5) are based upon (a) preventing conversion of AA to proinflammatory and prothrombotic eicosanoids; (b) serving as an alternate substrate for the five-series LTs that are less potent than four-series LTs; and (c) conversion by COX to threeseries prostanoids (i.e., $\mathrm{PGI}_{3}$ ) that also maintain antithrombotic actions. These and other explanations offered (Iigo et al., 1997; Calder, 2009; De Caterina, 2011) have not been generally accepted because of the lack of molecular evidence in vivo and the high concentrations of $\omega-3$ PUFA required to achieve putative "beneficial actions" in in vitro cell culture experiments. 


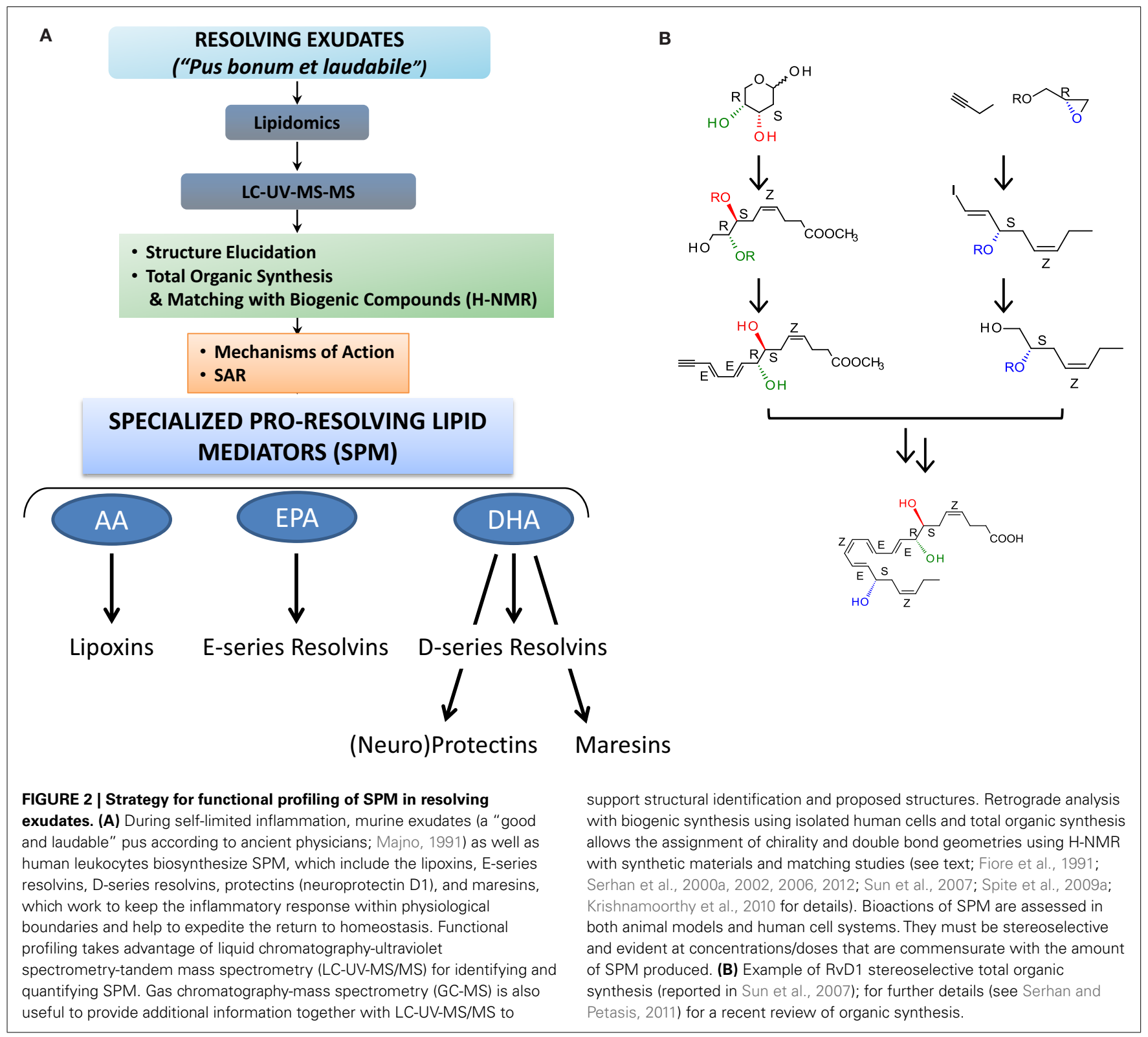

To address the molecular basis for anti-inflammatory properties of $\omega-3$ fatty acids, an unbiased LC-MS/MS-based informatics approach was developed to identify novel mediators generated from $\omega-3$ precursors during acute inflammation in vivo. Using this approach, EPA and DHA were found to be enzymatically converted into novel potent LMs coined Rv, an acronym of resolution phase interaction products, because they: (a) are produced during cell-cell interactions occurring in the resolution phase of acute inflammatory response; (b) "stop" further neutrophil entry to sites of inflammation, and (c) reduce exudates (Serhan et al., 2000a, 2002, 2006; Hong et al., 2003; Bannenberg et al., 2005). Rv represented an entirely new family of mediators produced from the $\omega-3$ fatty acids and importantly they appeared during the resolution phase via active biosynthetic processes. The biosynthesis of Rv gives rise to stereospecific local mediators that have potent actions and activate specific receptors.

\section{E-SERIES RESOLVINS}

EPA-derived E-series Rv are endogenously biosynthesized in vivo in resolving murine exudates and in isolated human cells systems by isolated cells (e.g., endothelial cell-leukocyte interaction) and in whole blood (vide infra). The complete stereochemistry of the first member of this family, RvE1, has been established as 5S,12R,18Rtrihydoxy-6Z,8E,10E,14Z,16E-EPA (Arita et al., 2005a). For further details on the total organic synthesis (see Serhan and Petasis, 2011). Within vascular endothelial cells, aspirin-acetylated COX2 converts EPA into 18R-hydro(peroxy)-eicosapentaenoic acid (HEPE), which is rapidly taken up by activated leukocytes (e.g., PMN) and further metabolized into RvE1. Notably, quantitative 


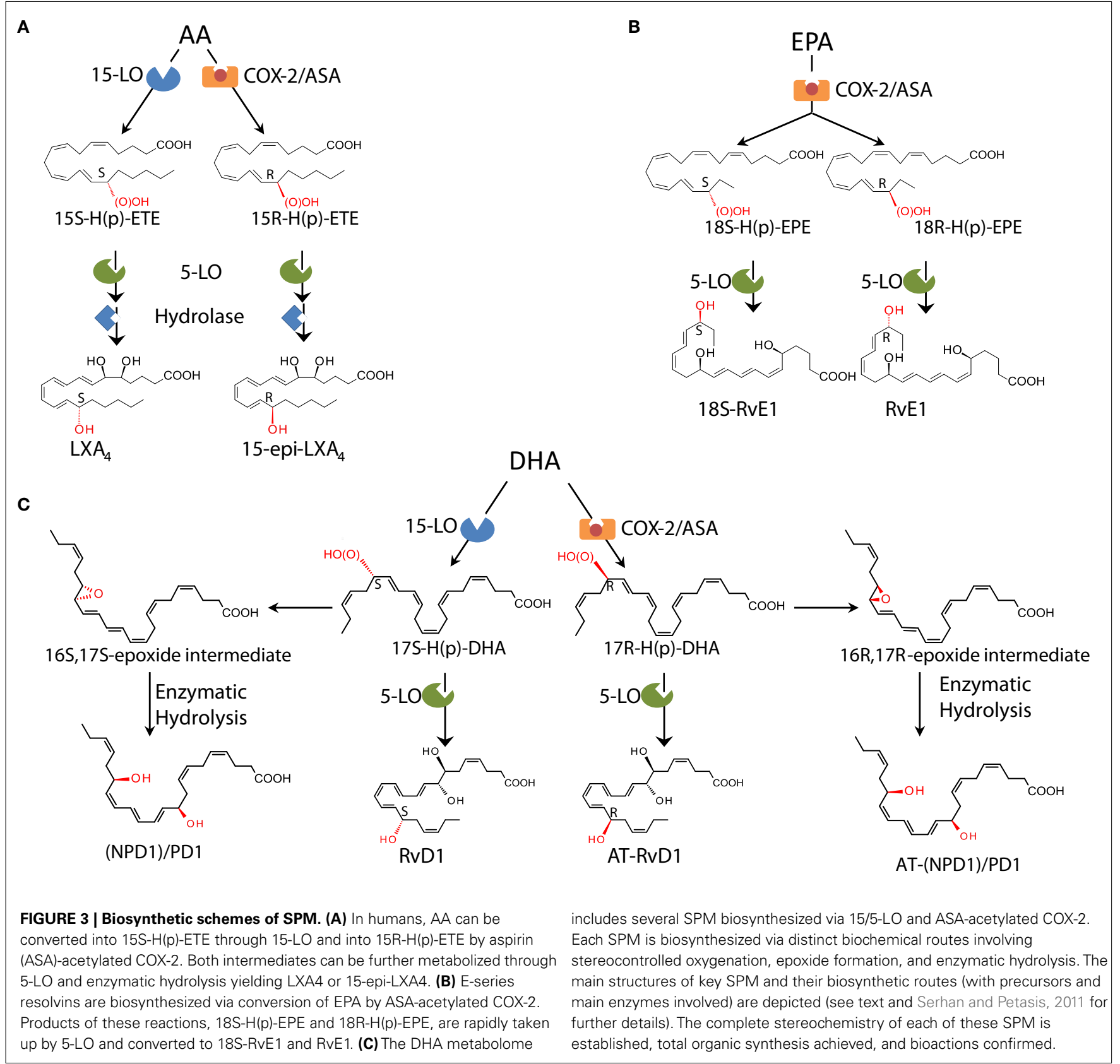

chiral HPLC analysis indicated that the 18R-HEPE isomer was dominant to its epimer $18 S$-HEPE in human plasma from healthy subjects taking EPA (Oh et al., 2011). In contrast, human subjects who were administered aspirin before EPA had more $18 S$ - than 18R-HEPE, indicating that aspirin might promote $18 S$-HEPE production as well as 18R-HEPE from ingested EPA (Oh et al., 2011). This $18 S$-HEPE can also be converted to epimeric RvE1 and RvE2 by human recombinant $5-\mathrm{LO}$ and $\mathrm{LTA}_{4}$ hydrolase $\left(\mathrm{LTA}_{4} \mathrm{H}\right)$, known as pro-inflammatory $\mathrm{LTB}_{4}$-synthesizing enzymes (Oh et al., 2011). RvE1 is also produced in vivo through an aspirin-independent pathway via cytochrome P450-driven oxygenation of EPA (Serhan et al., 2000b). Of interest, RvE1 was also found to be produced by Candida albicans and appears to be involved in clearance of this organism (Haas-Stapleton et al., 2007). Thus RvE1 has multiple biosynthetic routes. RvE2 (5S,18-dihydroxy-EPE) is biosynthesized in resolving exudates and in human whole blood via reduction of $5 S$-hydroperoxy,18-hydroxy-EPE, an intermediate in the biosynthetic pathway of RvE1 (Tjonahen et al., 2006; Ogawa et al., 2009; Oh et al., 2012; Figure 3).

\section{D-SERIES RESOLVINS}

Earlier investigations using LC-MS/MS lipidomics of resolving exudates from mice given DHA and aspirin provided the first evidence of novel endogenous routes that lead to the formation of 17-hydroxy-containing mediators. Gaining information on how human tissue and cells may produce D-series Rv involved 
the in vitro recapitulation of biosynthetic pathways using isolated human cells and recombinant enzymes establishing potential origins of novel compounds isolated from resolving exudates in vivo. Along these lines, hypoxic human endothelial cell COX-2 converted DHA to 13-hydroxy-DHA, which switched with ASA to 17R-HDHA. Human neutrophils transformed 17R-hydroxy-DHA into two series of di- and trihydroxy products; one initiated via oxygenation at carbon 7 and the other at carbon 4 (Serhan et al., 2002). The conversion of $17 R$-HDHA by human PMNs displayed similar features as those established for the conversion of AA to $\mathrm{LTB}_{4}$ or LXs as well as the $18 R$ series of EPA products. These were termed the "aspirin-triggered" D-series Rv (Serhan et al., 2002). Remarkably, in the absence of aspirin, D-series Rv carrying the 17S-hydroxy group were identified in murine exudates and isolated human cells (Serhan et al., 2002; Hong et al., 2003). The enzymatic pathway leading to the formation of $17 S$ - and $17 R-R v D 1$ is shown in Figure 3. Following the complete organic synthesis, the stereochemistry of 17S-, 17R-RvD1, and RvD2 were established as 7S,8R,17S-trihydroxy-4Z,9E,11E,13Z,15E,19Z-DHA (17S-RvD1), 7S,8R,17R-trihydroxy-4Z,9E,11E,13Z,15E,19Z-DHA (17R-RvD1; Sun et al., 2007), and 7S, 16R, 17S-trihydroxy-4Z, 8E, 10Z, 12E, 14E, 19Z-DHA (RvD2; Spite et al., 2009a). Additional members of this family were identified (RvD3-RvD6). Each of these arises by similar biosynthetic routes, but has distinct chemical structures and potentially additional bioactions that are now being unveiled (Chiang et al., 2012). Importantly, both RvE1 and RvD1 were identified in circulating blood of healthy donors by (Psychogios et al., 2011) as part of the Serum Metabolome Project.

\section{THE (NEURO)PROTECTINS}

In addition to D-series Rvs, DHA also serves as precursor of a new family of LM characterized by a conjugated triene system and two alcohol groups called PD. The name PD accounts for their protective actions observed in neural tissues and within the immune system, while the prefix neuro PD gives the tissue localization and site of action. The structure of the founding member of this family, PD1, was first disclosed in a report on the isolation and elucidation of Rv (Serhan et al., 2002; Hong et al., 2003), and its complete stereochemistry later established as $10 R, 17 S$-dihydroxy-docosa$4 Z, 7 Z, 11 E, 13 E, 15 Z, 19 Z$-hexaenoic acid (Serhan et al., 2006). In addition to PD1, several stereo- and positional isomers that also possess lower bioactivity than PD1 were identified in human and mouse tissues. These include 10S,17S-diHDHA, 4S,17S-diHDHA, $7 S, 17 S$-diHDHA, and 22-hydrox-10,17S-docosatriene (a putative inactivation product of PD1; Serhan et al., 2002; Hong et al., 2003). The geometry of the double bonds in PD1, their positions during biosynthesis, and chirality of C10 indicate that PD1 biosynthesis proceeds through a C16(17)-epoxide intermediate and requires specific enzymatic steps to generate the potent bioactive molecule from DHA, as confirmed by the isolation of alcohol trapping products as well as two vicinal diol 16,17-docosatrienes as minor products of PD1 biosynthesis (Hong et al., 2003; Serhan et al., 2006). Recently, a novel aspirin-triggered COX-2 driven pathway was reported that biosynthesizes the $17 \mathrm{R}$-epimeric form of PD1 from DHA (Marcheselli et al., 2003; Figure 3). The total organic synthesis and complete stereochemical assignment of AT-PD1 (10R,17R- dihydroxy-docosa-4Z,7Z,11E,13E,15Z,19Zhexaenoic acid) were recently achieved. Both PD1 and AT-PD1 reduced leukocyte infiltration in murine peritonitis, reduced PMN transmigration with endothelial cells, and enhanced efferocytosis of apoptotic PMN by human MФ (Serhan et al., 2006). These are the hallmark actions of a SPM carrying both anti-inflammatory and pro-resolving actions demonstrable both in vitro and in vivo.

\section{MARESINS}

MФs have pivotal roles in orchestrating the return to homeostasis (Gordon, 2007) and biosynthesize SPM that enhance their pro-resolving and homeostatic functions. For example, $\mathrm{M} \Phi$ ingesting apoptotic cells initiate the biosynthesis of $\mathrm{LXA}_{4}, \mathrm{RvE1}$, and PD1 but not $\mathrm{LTB}_{4}$ (Freire-de-Lima et al., 2006; Schwab et al., 2007). In addition, a new family of SPM biosynthesized by MФs was identified (Serhan et al., 2009). Unbiased LM LC-MS/MSbased metabololipidomics during self-limited peritonitis led to the identification of a novel pathway that converted DHA into 14-hydroxy DHA (HDHA). Experiments with $12 / 15-\mathrm{LO}^{-1-}$ mice or with LO inhibitor confirmed that 14-HDHA production was via a DHA carbon 14 lipoxygenation pathway. Freshly prepared $14-\mathrm{H}(\mathrm{p}) \mathrm{DHA}$ is rapidly converted by isolated human and mouse $\mathrm{M} \Phi$ into a new set of bioactive products, whose molecular structure was established (Serhan et al., 2009) and recently confirmed by matching of biogenic material with those prepared by total organic synthesis (Serhan et al., 2012). The major product of this new pathway proved to be 7,14-dihydroxydocosa-4Z,8E,10E,12Z,16Z,19Zhexaenoic acid, denoted MaR (macrophage mediator in resolving inflammation) 1 (first in the family; MaR1; Serhan et al., 2009). Similar to that of other potent SPM, MaR1 biosynthesis proceeds via an epoxide intermediate, specifically the MaR1 13,14-epoxide intermediate, that was demonstrated by trapping experiment and with ${ }^{18} \mathrm{O}$-containing molecular oxygen $\mathrm{O}_{2}$ that opens during enzymatic conversion to MaR1 keeping the double bond geometry and chirality of carbon 7 and 14 .

In addition to MaR1 in resolving murine exudates, a novel double dioxygenation product was isolated and identified, $7 S, 14 S$-dihydroxydocosa-4Z,8E,10Z,12E,16Z,19Z-hexaenoic acid (denoted 7S,14S-diHDHA), formed by consecutive lipoxygenation of 14-HDHA, was also identified using molecular oxygen incorporation, and proved bioactive but less potent in activity than MaR1 in stimulating efferocytosis with human cells (Serhan et al., 2009, 2012). MaR1 and RvE1 are also potent stimulators of organ regeneration using a planaria regeneration system (Serhan et al., 2012). Hence, SPM are primordial molecules that signal from the inflammatory site to generate the aftermath of inflammation and tissue injury.

\section{GPCRS FOR SPM IN ANTI-INFLAMMATION AND RESOLUTION GPCRs FOR LXs}

The first evidence for receptor-mediated actions of $\mathrm{LXA}_{4}$ arises from studies with Santosh Nigam when he was on sabbatical in the Serhan Lab at BWH in the late 1980s, which demonstrated stimulation of rapid lipid remodeling and pertussis toxin (PTX)-sensitive release of arachidonate in PMN treated with $\mathrm{LXA}_{4}$ (Nigam et al., 1990). To examine the molecular basis of these actions, synthetic $\left[11,12-{ }^{3} \mathrm{H}\right]-\mathrm{LXA}_{4}$ was prepared and used to demonstrate specific and reversible binding to intact human $\mathrm{PMN}$ with a $K_{\mathrm{d}} \sim 0.5 \mathrm{nM}$. $\left[{ }^{3} \mathrm{H}\right]$-LXA 4 binding was stereoselective as $\mathrm{LXB}_{4}, \mathrm{LTB}_{4}, 6 \mathrm{~S}-\mathrm{LXA}_{4}$, or 11-trans- $\mathrm{LXA}_{4}$ did not compete for $\mathrm{LXA}_{4}$ binding, while cysteinyl 
LT $\mathrm{C}_{4}$ and $\mathrm{D}_{4}$ partially displaced bound labeled $\mathrm{LXA}_{4}$ (Fiore et al., 1992). Screening of cDNA clones from differentiated HL60 human cells lines led to the identification of formyl peptide receptor like1, a homolog of formyl receptor, as putative $\mathrm{LXA}_{4}$ GPCR (Fiore et al., 1994). This receptor has recently been coined ALX/FPR2 by the international nomenclature committee in light of its high affinity for $\mathrm{LXA}_{4}$ (Ye et al., 2009).

Human FPR2/ALX is highly expressed in myeloid cells and at a lower extent in lymphocytes, dendritic cells, and resident cells (Chiang et al., 2006). Orthologs of the human FPR2/ALX have been identified in mice (Takano et al., 1997) and rats (Chiang et al., 2003). In addition to LXA 4 , FPR2/ALX is activated by the glucocorticoid-induced protein annexin-1 and its N-terminal peptides (Perretti et al., 2002), representing the prototype of GPCR able to coordinate anti-inflammatory and pro-resolving activities of both lipid and peptide ligands. Genetic manipulation of ALX/FPR2 and its ortholog in mice has provided evidence for the essential role of this GPCR in controlling immune responses. Indeed, myeloid-driven overexpression of human FPR2/ALX in transgenic mice resulted in a reduced neutrophil infiltration during zymosan-induced peritonitis (Devchand et al., 2003), whereas ALX/FPR $2^{-1-}$ mice have an exacerbated inflammatory phenotype and delayed resolution (Dufton et al., 2010).

More strikingly, ATL and FPR2/ALX expression levels dictate both the magnitude and duration of acute inflammation in humans (Morris et al., 2010). Hence, mechanisms that regulate this expression are of wide interest. Recent results from Simiele et al. (2012) uncovered the molecular basis of ALX/FPR2 transcription machinery, with the identification of the core promoter sequence, the elucidation of transcription factors and epigenetic mechanisms that regulate promoter activity, and the identification of the first inheritable SNP that impairs promoter activity in individuals at high cardiovascular risk. Notably, LXA 4 upregulates ALX/FPR2 levels by activating its promoter, suggesting an additional mechanism by which $\mathrm{LXA}_{4}$ exerts its bioactivities (Simiele et al., 2012). This is particularly relevant in considering LX roles in stimulating resolution. In addition, earlier studies demonstrated that radiolabeled 15-epi-LXA 4 binds at cysteinyl LT receptor 1 (CysLT1) with equal affinity to $\mathrm{LTD}_{4}$, providing additional molecular mechanisms for ATL dampening CysLT signals in the vasculature as well as regulating leukocyte trafficking via ALX/FPR2 (Gronert et al., 2001).

\section{GPCRS FOR E-SERIES RESOLVINS}

At least two GPCRs are involved in mediating RvE1 actions, namely ChemR23 and BLT1 (Arita et al., 2005a, 2007). RvE1 binding to ChemR23 was assessed with $\left[{ }^{3} \mathrm{H}\right]$-labeled RvE1, which was prepared by catalytic hydrogenation from synthetic diacetylenic RvE1. $\left[{ }^{3} \mathrm{H}\right]-\mathrm{RvE} 1$ bound to ChemR23 transfectants with high affinity $\left(K_{\mathrm{d}}=11.3 \pm 5.4 \mathrm{nM}\right)$ and stereoselectivity, since RvE1 biogenic precursors EPA and $18 R$-HEPE did not compete with $\left[{ }^{3} \mathrm{H}\right]-\mathrm{RvE} 1$. Also, the synthetic peptide fragment (YHSFFFPGQFAFS) derived from human chemerin that was earlier reported to be a ligand for this same receptor (Wittamer et al., 2003) displaced $\left[{ }^{3} \mathrm{H}\right]-\mathrm{RvE} 1$ binding by $\sim 70 \%$ when tested at $10 \mu \mathrm{M}$ concentration, suggesting that RvE1 and chemerin share recognition sites on ChemR23 (Arita et al., 2005a; Ohira et al., 2009). [ $\left.{ }^{3} \mathrm{H}\right]$-RvE1 specific binding was also demonstrated with membrane fractions isolated from human PMN. Radiolabeled RvE1 bound human PMN with $K_{\mathrm{d}}$ of $\sim 50 \mathrm{nM}$ and was displaced by homoligand $\operatorname{RvE} 1\left(K_{\mathrm{i}} \sim 34 \mathrm{nM}\right)$, $\mathrm{LTB}_{4}\left(K_{\mathrm{i}}=0.08 \mathrm{nM}\right)$, and $\mathrm{LTB}_{4}$ receptor 1 (BLT1) selective antagonist U-75302 $\left(K_{\mathrm{i}}=1.5 \mathrm{nM}\right)$, but not by the chemerin peptide (Arita et al., 2007). These results strikingly demonstrated that RvE1 binding sites are pharmacologically distinct from ChemR23 on human PMN and prompted us to investigate whether RvE1 binds to $\mathrm{LTB}_{4}$ receptors.

In these studies, Arita et al. found that $\left[{ }^{3} \mathrm{H}\right]-\mathrm{RvE} 1$ also gave high affinity binding to recombinant BLT1 $\left(K_{\mathrm{d}} \sim 45 \mathrm{nM}\right)$ that was competed by unlabeled $\mathrm{LTB}_{4}\left(K_{\mathrm{i}}=3 \mathrm{nM}\right)$. In contrast, BLT2overexpressing cells did not show $\left[{ }^{3} \mathrm{H}\right]-\mathrm{RvE} 1$ binding at concentrations up to $10 \mathrm{nM}$. These results clearly demonstrated that RvE1 binds to BLT1 on human PMN and acts as a partial agonist to attenuate $\mathrm{LTB}_{4}$ incoming signals in both mouse and human leukocytes (Arita et al., 2007).

Profiling for tissue distribution of human ChemR23 showed expression of this GPCR in brain, kidney, cardiovascular, gastrointestinal, and myeloid tissues (Arita et al., 2005a). More recently, direct evidence for ligand-receptor interactions of RvE1 and its epimer 18S-RvE1 was provided using ChemR23 and BLT1 $\beta$ arrestin cells. In this system, cells were engineered to co-express a $\beta$ arrestin protein tagged with an inactive moiety of $\beta$-galactosidase enzyme together with a candidate GPCR fused to the short ProLink peptide derived from $\beta$-galactosidase. In the presence of ligand, in this context RvE1 activates GPCR interacts with $\beta$-arrestin, bringing to proximity two inactive portions of $\beta$-galactosidase and reconstituting the fully active enzyme. The activity of this enzyme, which is stoichiometrically dependent on GPCR-ligand interaction, is monitored with a chemiluminescence detection system. With ChemR23 $\beta$-arrestin cells, $18 S$-RvE1 dose-dependently activated ChemR23 receptor, with $\mathrm{EC}_{50}(\sim 6.3 \mathrm{pM})$ lower than that obtained with RvE1 ( 0.14 nM). 18S-RvE1 also antagonized $\mathrm{LTB}_{4}$-mediated BLT1 activation with higher potency and efficacy than RvE1 in BLT1 $\beta$-arrestin cells (Oh et al., 2011). Hence, RvE1 and $18 S-R v E 1$ can share the same site(s) of specific binding to human ChemR23 as well as BLT1 and thus suggest location-dependent mechanisms in their signaling capabilities.

RvE2 exerts potent and cell-specific bioactions on human leukocytes (Tjonahen et al., 2006; Oh et al., 2012). Recently, tritium-labeled $\left[{ }^{3} \mathrm{H}\right]$-RvE2 was synthesized and gave comparable $K_{\mathrm{d}}(\sim 25 \mathrm{nM})$ with other SPM in isolated human PMN. In addition, using ChemR23 and BLT1 $\beta$-arrestin cells, RvE2 was found to share, at least in part, receptors with RvE1 (Oh et al., 2012).

\section{GPCRS FOR D-SERIES RESOLVINS}

RvD1 activates its own GPCR and does not activate ChemR23. RvD1 exerts specific bioactivities on human PMN, namely reduction of F-actin polymerization, that are inhibited by PTX but not cholera toxin, whereas it did not stimulate $\mathrm{Ca}^{2+}$ release nor activate cAMP in human PMN (Krishnamoorthy et al., 2010). For the purpose of investigating direct binding of $\mathrm{RvD} 1$ to human PMN, $\left[{ }^{3} \mathrm{H}\right]-\mathrm{RvD} 1$ was prepared by catalytic hydrogenation of synthetic $[13,14]$-acetylenic RvD1 methyl ester by custom tritiation (American Radiolabel; Krishnamoorthy et al., 2010). This procedure was followed by de-esterification and isolation of the RvD1 label using RP-HPLC. $\left[{ }^{3} \mathrm{H}\right]-\mathrm{RvD} 1$ specifically bound to human PMN with high affinity $\left(K_{\mathrm{d}} \sim 0.17 \mathrm{nM}\right)$ and was competed 
by homoligand cold RvD1 (100\%) and $\mathrm{LXA}_{4}(\sim 60 \%)$ but not the ALX-ligand annexin-1-derived Ac2-12 peptide. In parallel, $\left[{ }^{3} \mathrm{H}\right]-\mathrm{RvD} 1$ also showed specific binding with human monocytes (Krishnamoorthy et al., 2010). Since RvD1 counteracts TNF- $\alpha$ in vivo, luciferase-based reporter system (Arita et al., 2005a) was employed in functional screenings to assess the ability of selected GPCRs (Figure 4) to transduce RvD1 signals that block NF- $\mathrm{B}$ activity in response to TNF- $\alpha$.

Phylogenetically related GPCR linked to inflammation and chemoattraction were overexpressed into HeLa cells together with a reporter vector consisting of NF- $\kappa \mathrm{B}$ promoter sequence linked to the luciferase gene. RvD1 significantly reduced TNF$\alpha$-stimulated NF- $\kappa \mathrm{B}$ response in cells overexpressing either the LX receptor ALX/FPR2 or the orphan, GPR32, but not other GPCRs (e.g., BLT1, BLT2, CB1, GPR-1, FPR, and ChemR23; Krishnamoorthy et al., 2010). Moreover, RvD1 dose-dependently activated ALX/FPR2 and GPR32 in recombinant $\beta$-arrestin cells with $\mathrm{EC}_{50}$ in the low picomolar range $\left(\mathrm{EC}_{50} \sim 1.2 \mathrm{pM}\right.$ for ALX/FPR2; $8.8 \mathrm{pM}$ for GPR32; Figure 5). In contrast, RvD1 did not activate RvE1 receptor ChemR23, demonstrating the high selectivity of these ligands for their specific GPCR (Krishnamoorthy et al., 2010). In comparison, at equimolar concentrations, RvD1, its epimer AT-RvD1, RvD1-carboxy-methyl ester, and a metabolically more stable analog 17 (R/S)-methyl RvD1-ME activated both ALX/FPR2 and GPR32 with similar potencies and EC $_{50}$, whereas the biosynthetic precursor native DHA was not active with GPR32 and ALX/FPR2 in this concentration (Krishnamoorthy et al., 2012). Of interest, the known anti-inflammatory ALX/FPR2 agonist compound 43 identified by traditional medicinal chemistry screening also activated GPR32 $\left(\mathrm{EC}_{50} \sim 2.2 \mathrm{pM}\right)$ and ALX/FPR2 $\left(\mathrm{EC}_{50} \sim 2.0 \mathrm{pM}\right)$ in $\beta$-arrestin cells but not the $\mathrm{ADP}$ receptor $\mathrm{P} 2 \mathrm{Y}_{12}$ (Krishnamoorthy et al., 2010). Hence, RvD1, AT-RvD1, and the derivatives carboxy methyl ester and $17(\mathrm{R} / \mathrm{S})$-RvD1 directly activate ALX/FPR2 and GPR32, hereafter referred to as RvD1 receptor (DRV1) following the IUPAC recommendations for receptor nomenclature (Brink et al., 2003; Figure 5). Overexpression of either ALX/FPR2 or GPR32 in human MФs gave further enhancement of efferocytosis in response to RvD1, while knockdown of ALX/FPR2 or DRV1/GPR32 determined a decrease in RvD1-stimulated phagocytosis response (Krishnamoorthy et al., 2010).

In keeping with this, Norling et al. (2012) demonstrated that the ability of RvD1 to reduce human PMN-endothelial cell interactions is absolutely dependent on ALX/FPR2 and DRV1/GPR32. Interestingly, actions of low concentration ( $1 \mathrm{nM})$ RvD1 were dampened by DRV1/GPR32 blocking antibody, whereas at high concentrations $(10 \mathrm{nM})$ they appeared ALX/FPR2-specific. These two receptors also have distinct responses in an activated cell environment in that upon activation human PMN rapidly mobilized ALX/FPR2 stored in secretory granules, but not DRV1/GPR32, to the cell membrane. In addition, in ALX/FPR2 knockout mice RvD1 did not exert anti-inflammatory (e.g., stop PMN infiltration) nor pro-resolving (e.g., enhancing $M \Phi$ efferocytosis) actions (Norling et al., 2012). Hence, specific GPCRs selectively mediate RvD1 actions with ALX/FPR2 being rapidly upregulated in PMN that are exposed to pro-inflammatory stimuli and DRV1/GPR32 possibly conveying more homeostatic functions. With respect to cell and tissue distribution, ALX/FPR2 is present on leukocytes and resident cells (including $\mathrm{M} \Phi$, synovial fibroblasts, mesangial cells, endothelial, and epithelial cells; Krishnamoorthy et al., 2010). Human DRV1/GPR32 was identified in peripheral blood leukocytes and arterial and venous tissues using a cDNA array. It is mostly abundant on PMN, monocytes, and macrophages and is also present on vascular endothelial cells (Krishnamoorthy et al., 2010). The murine ortholog of DRV1/GPR32 is currently not known but is present in chimpanzees. Regulatory mechanisms of DRV1/GPR32 are of interest while those of ALX/FPR2 have recently been uncovered (Simiele et al., 2012). Although specific receptors for RvD2, RvD3, and RvD4 have not yet been identified, the stereoselective actions of RvD2 were inhibited by PTX (Spite et al., 2009a), implicating the involvement of GPCRs. More recently, Chiang et al. (2012) reported activation of RvD1-receptor DRV1/GPR32 by RvD5, which is related biosynthetically to RvD1, with the recombinant human DRV1.

\section{GPCRs FOR NEURO (N)PD1/PD1}

Biosynthesis of $(\mathrm{N}) \mathrm{PD} 1$ occurs in neural tissues in response to injury, ischemia-reperfusion, and exposure to $\beta$-amyloid peptides (Marcheselli et al., 2003; Mukherjee et al., 2004; Bazan, 2007). In addition (N)PD1 shows protective anti-inflammatory and pro-resolving actions within the immune system (Serhan et al., 2002; Hong et al., 2003). Hence, it was of interest to determine the molecular basis of (N)PD1/PD1 actions. Specific binding of tritium-labeled (N)PD1 obtained by catalytic tritiation of synthetic 15-acetylenic NPD1 methyl ester was demonstrated with both retinal pigment cells (RPE) and human PMN. $\left[{ }^{3} \mathrm{H}\right]-(\mathrm{N}) \mathrm{PD} 1$ bound RPE with $K_{\mathrm{d}} \sim 30 \mathrm{pmol} / \mathrm{mg}$ of cell protein. However, at high concentration of radio-ligand ( $>10 \mathrm{nM})$, non-specific binding was evident, in line with the highly hydrophobic nature of this compound. In these experiments, competitive binding studies with unlabeled ligand demonstrated $90-100 \%$ displacement for the free acid form of cold (N)PD1. In these studies (N)PD1-ME showed a lower affinity for binding sites and $\sim 74 \%$ displacement, while other structurally related omega-3 fatty acid-derived compounds (17S-hydroxy-DHA, RvE1, $\Delta 15$-trans-NPD1, and $\Delta 15$-trans-NPD1-carboxy methyl ester) gave only minimal or no displacement. Specific binding experiments with $\left[{ }^{3} \mathrm{H}\right]-\mathrm{NPD} 1$ and isolated human PMN proved high affinity specific binding and showed a two-site fit for sites of high and low affinity binding $\left(K_{\mathrm{d}} \approx 25\right.$ and $\left.200 \mathrm{nM}\right)$. Two other SPM that bind specific receptors on human PMN, namely $\mathrm{LXA}_{4}\left(\mathrm{LXA}_{4}\right)$ and RvE1, did not compete with $\left[{ }^{3} \mathrm{H}\right]-\mathrm{NPD} 1$ binding on these cells (Marcheselli et al., 2010).

\section{HOW DO THE PRO-RESOLVING MEDIATORS WORIK?}

By definition, SPM: (a) are generated within the resolution phase; (b) limit leukocyte infiltration; (c) enhance phagocytic activity of pro-resolving $M \Phi$ to remove apoptotic cells and/or microbes; (d) stimulate the clearance of PMN from mucosal surfaces and their anti-microbial actions. If a LM fulfills each of these bioactivities, then it belongs to the genus of SPM. At the cellular and molecular levels, SPM display distinct modes of action on PMN and monocyte/M $\Phi$ s, which can be demonstrated with isolated cells. Each SPM (RvE1, RvE2, and RvD1) stimulates a rapid shape change of human leukocytes that reflects ligand-receptor responses and cytoskeletal events that ultimately limit the PMN to diapedesis 


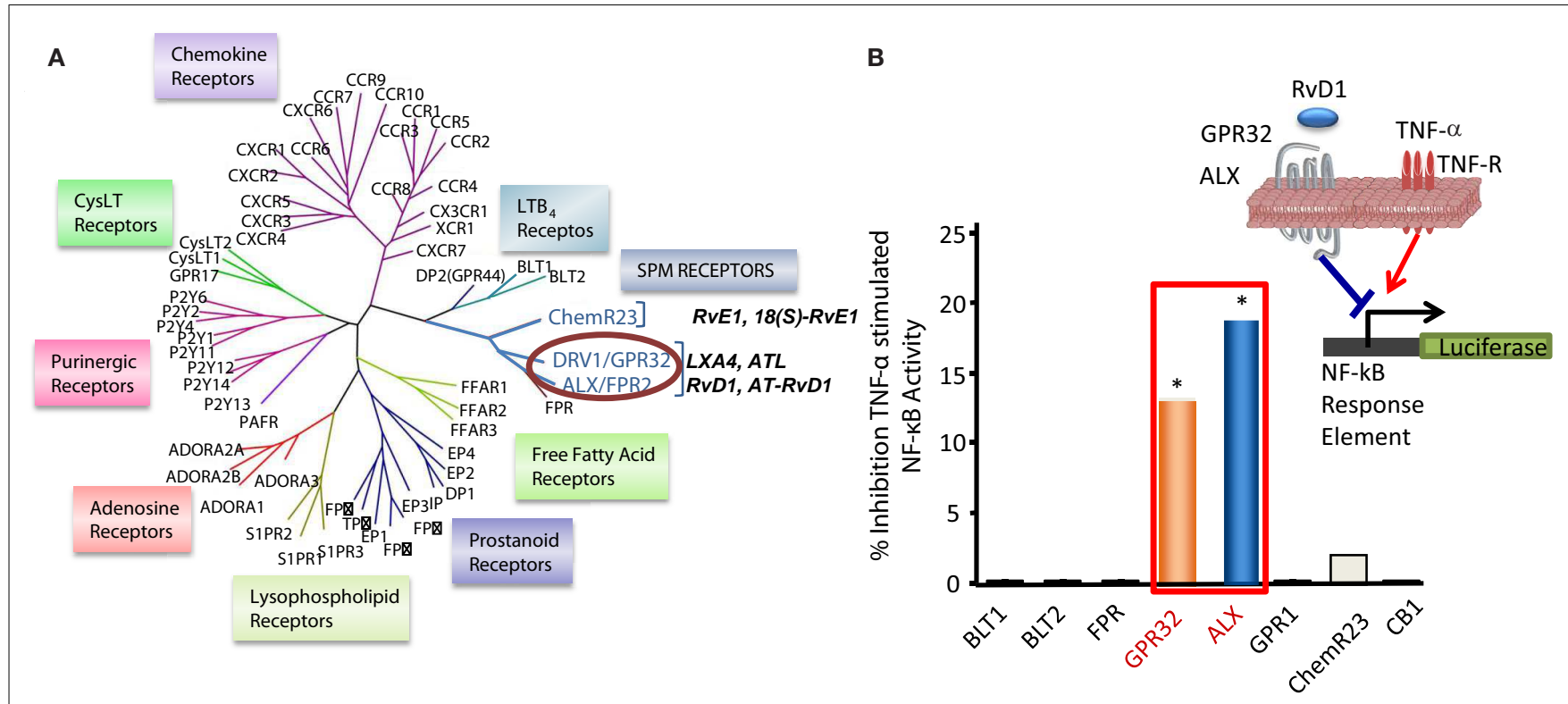

FIGURE 4 | Identification of RvD1 GPCR. (A) Phylogenetic tree shows similarities in the amino acid sequences of human GPCRs closely related to $\mathrm{LXA}_{4}, \mathrm{RvE} 1$, and $\mathrm{LTB}_{4}$ receptors (left panel). Cluster was generated with the ClustalW2 software (www.ebi.ac.uk/Tools/clustalw2). Protein sequences were deduced from the NCBI database and receptor nomenclature followed the IUPAR classification for GPCR. (B) For functional screening and identification of RvD1 receptor, GPCRs were cloned in pcDNA3 vector and overexpressed in human HeLa cells cotransfected with pNF-кB luciferase plasmid. Cells were treated with RvD1 and TNF- $\alpha$ (see inset in the right panel). RvD1 reduces TNF- $\alpha$-stimulated NF- $\mathrm{B}$ activation in DRV1/GPR32 and ALX/FPR2 receptor-overexpressing cells, while cells transfected with other related GPCRs (e.g., BLT1, BLT2, CB1, GPR-1, FPR, and ChemR23) did not significantly inhibit TNF- $\alpha$-induced NF-кB luciferase activity on addition of the ligand RvD1. The results illustrated are expressed in luminescence units subtracted from pNF-kB and pcDNA3 empty vector $\left({ }^{*} P<0.05\right.$ vs. BLT2-transfected cells).

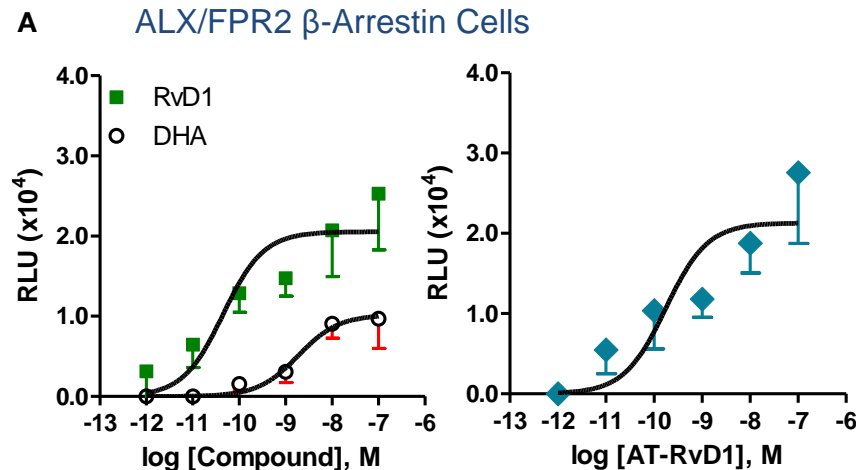

FIGURE 5 | Structure-activity relationship of RvD1, AT-RvD1, and DHA on ALX/FPR2 and DRV1/GPR32 receptors. Activation of ALX/FPR2 and DRV1/GPR32 was determined using the $\beta$-arrestin cell system. This system is engineered by stably expressing the target ALX/FPR2 or DRV1/GPR32 tagged with the $\beta$-galactosidase Pro-Link peptide. Cells also co-expressed the $\beta$-arrestin protein linked to the $\beta$-galactosidase EA fragment. In the presence of ligand, activated GPCR interacts with $\beta$-arrestin, bringing to proximity the EA and Pro-Link
B
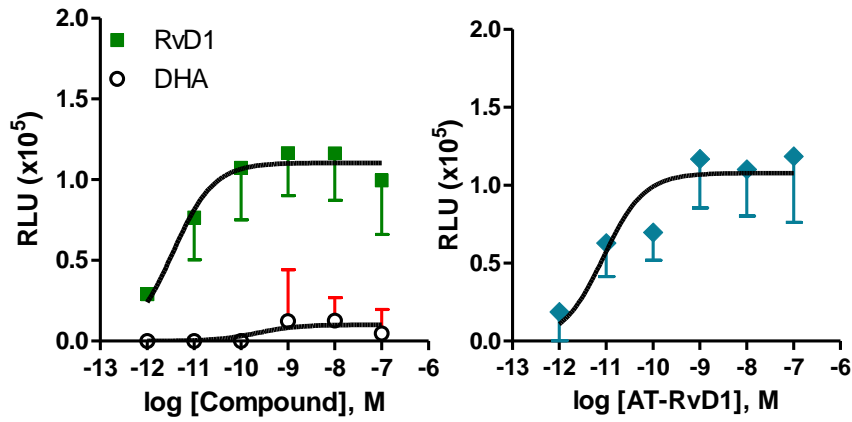

fragments, forming a functional enzyme. $\beta$-galactosidase activity is measured by adding the substrate and generating a chemiluminescent signal that is stoichiometrically associated to ligand dependent GPCR activation (see text and Krishnamoorthy et al., 2010 for further details). Dose-response curves show activation of ALX/FPR2 (A) and DRV1/GPR32 (B) receptors by RvD1, AT-RvD1, but not DHA determined using the $\beta$-arrestin cell system. Results are mean ( \pm SEM) from $n=4$ to 6 . RLU, relative luminescence unit. in vivo, hence reducing inflammation and tissue damage (Dona et al., 2008; Kasuga et al., 2008; Oh et al., 2012) and prepare the macrophages to enhance phagocytosis of both apoptotic cells and microbes (Schwab et al., 2007; Ohira et al., 2009).
The best examples of these pro-resolving cellular mechanisms studied to date are for the Rv ligands RvE1 and RvD1. In the case of RvE1, its direct binding to the human recombinant GPCR denoted ChemR23, an RvE1 receptor, activates the receptor with the subsequent regulation of Akt intracellular signaling pathway and 
phosphorylation signaling of proteins that increase phagocytosis (Ohira et al., 2009). In the case of RvD1, the ligand reduces actin polymerization in isolated human PMN in a PTX-sensitive manner (Krishnamoorthy et al., 2010), diminishes surface expression of CD11b involved in leukocyte adhesion to endothelial cells (Krishnamoorthy et al., 2010) as does RvE1 (Dona et al., 2008), evokes a shape change and stops chemoattractant-initiated PMN migration observable at a single cell level with human cells isolated within microfluidic chamber systems (Kasuga et al., 2008). Of note, $\mathrm{LXA}_{4}$ also stops PMN chemotaxis in vitro (reviewed in Serhan, 2005), while it induces rapid activation of small GTPases and redistribution of cytoskeletal proteins (e.g., MYH9, F-actin) in human monocyte-derived M $\Phi$ s during phagocytosis (Maderna et al., 2002; Reville et al., 2006). Hence, there appears to be a general mechanism on how pro-resolving molecules work to achieve their potent anti-inflammatory and pro-resolution actions, namely via SPM coupling to distinct high affinity receptors that evoke cell-type and specific intracellular pathways.

Besides these general actions, each SPM possesses additional specific activities (see Table 1; Fredman and Serhan, 2011). Given the important protective function of acute inflammation to fight infections or dangers from within and the need to safeguard the host from an uncontrolled reaction, it is not surprising that SPM have some bioactions overlapping in target tissues and specific cell types. In addition, the sites of biosynthesis for each SPM and the degree of cell distribution of their GPCRs may underlie selectivity and specificity of the pro-resolving system. In experimental models of inflammation and resolution, SPM proved to be stereoselectively active in the nano- to low microgram dose range to control inflammation, limit tissue damage, shorten resolution intervals, promote healing, and alleviate pain (Table 1). In order to define resolution in unbiased, quantitative terms, mathematical resolution indices were introduced for determining the cellular changes in exudates, i.e., $T_{\max }$, time point of maximum PMN infiltration $\left(\Psi_{\max }\right) ; T_{50}$, time necessary to achieve $50 \%$ reduction in PMN number $\left(\Psi_{50}\right)$ from $\Psi_{\max }$; resolution interval $\left(R_{\mathrm{i}}=T_{50}-T_{\max }\right)$, time interval between $T_{\max }$ and $T_{50}$ (Bannenberg et al., 2005). The introduction of resolution indices permits the evaluation of pro-resolution bioactions of endogenous chemical mediators or pharmacological agents (Schwab et al., 2007; Haworth et al., 2008; Navarro-Xavier et al., 2010). These results first demonstrate the possibility to pharmacologically manipulate resolution and stimulate resolution. Along these lines, results from the first human Phase III clinical trials demonstrated the safety and efficacy of a $\mathrm{Rv}$ analog that reduces both signs and symptoms of dry eye syndrome (http://Clinicaltrials.Gov Identifier: NCT00799552) and have moved forward to Phase III clinical trial with Celtic Therapeutics. Dye eye syndrome is a chronic illness commonly treated with the immune-suppressant cyclosporine, providing evidence that SPM have the potential to treat a broad array of human diseases.

Acute inflammation following tissue injury, surgery, or infections causes pain (Majno and Joris, 1996). Peripheral sensitization of primary sensory neurons is induced by inflammatory mediators released after tissue insults, such as bradykinin, prostaglandins, nerve growth factors (NGF), pro-inflammatory cytokines such as TNF- $\alpha$, interleukin (IL)- $1 \beta$ and IL- 6 , and pro-inflammatory chemokines (Stein et al., 2009). The contribution of $\mathrm{PGE}_{2}$ and $\mathrm{I}_{2}$ led to the use of NSAID (e.g., naproxen, ibuprofen) and selective COX-2 inhibitors as analgesic. Since SPM are potent regulators of acute inflammation and pro-inflammatory mediators (including PGs, TNF- $\alpha$, and IL-1 $\beta$ ), and since COX-2 inhibitors are resolution toxic (Schwab et al., 2007), it was of interest to investigate whether SPM could control inflammation associated and chronic pain. The initial report from Svensson et al. (2007) on the antinociceptive actions of $\mathrm{LXA}_{4}$ was followed by further studies demonstrating that Rvs, PD, and also MaR1 have potent analgesic activities when administered both locally and systematically (Xu et al., 2010; Huang et al., 2011; Lima-Garcia et al., 2011; Park et al., 2011; Serhan et al., 2012). Notably, the exquisite potent actions of SPM, which proved as effective as morphine and COX-2 inhibitor NS398 at much lower doses (Xu et al., 2010), occur without altering basal sensitive perception, unlike other anesthetics used to control pain during surgery. Hence it appears possible to resolve pain signaling as well as inflammation.

Complete resolution requires regeneration of destroyed tissues without affecting their functionality as in the case of fibrosis or scarring. Pro-resolving $M \Phi$ play key functions in tissue remodeling under both homeostatic (e.g., post parturition) and pathological (e.g., removal of microbes from infected tissues) conditions (Honn et al., 1989; Majno and Joris, 1996; Gordon, 2007). In this regard, SPM are of considerable interest in view of their roles in regulating $\mathrm{M} \Phi$ activities. For instance, $\mathrm{LX}, \mathrm{Rv}$, and PD stimulate the non-phlogistic efferocytosis by M $\Phi$ (Godson et al., 2000; Schwab et al., 2007; Hong et al., 2008; Krishnamoorthy et al., 2010; Oh et al., 2011). In addition, RvD1 regulates $M \Phi$ accumulation in diabetic obese mice (Hellmann et al., 2011) and reduces arthritic pain (Xu et al., 2010; Lima-Garcia et al., 2011). Failure in the $М \Phi$-driven pro-resolution program can support persistent inflammation associated with many human diseases, such as periodontitis. In keeping with this, recent reports indicate that $M \Phi$ from localized aggressive periodontitis have impaired phagocytosis and persistent inflammation that is rescued with RvE1 (Fredman et al., 2011). In addition to enhancing MФ phagocytosis, MaR1 biosynthesized in vivo during tissue injury repair also accelerated tissue regeneration in planaria ( $D$. tigrina) after surgical head removal (Serhan et al., 2012). Of note, these actions of MaR1 were inhibited by PTX, indicating the involvement of GPCR and related signaling in this process (Serhan et al., 2012).

\section{miRNAS IN RESOLUTION CIRCUITS}

Results from the Serhan laboratory at Brigham and Women's Hospital-Harvard Medical School demonstrated for the first time that SPM are operative in resolution and act locally to control leukocyte trafficking, regulate chemical mediators (e.g., cytokines, chemokines, and lipid autacoids), and expedite the return to homeostasis. Since microRNA (miRNAs) have emerged as the fine tuners of many cellular processes, including immune responses and cancer, it was of interest to investigate whether they also played roles in resolution and SPM-regulated specific miRNA as part of their mechanisms of action. To identify a miRNA signature of resolution in self-resolving exudates, a strategy with resolving exudates from murine peritonitis was used (Figure 6). Zymosan A particles from S. cerevisiae, a Toll-like receptor 2 and 4 ligand, were injected i.p. and peritoneal exudates collected to 
Table 1 | Bioactions of SPM.

\section{SPM}

Lipoxin A4/ATL

\section{Disease model}

Mouse/dermal inflammation
Mouse/dorsal air pouch
Rabbit/periodontitis
Mouse/peritonitis
Mouse/colitis

Mouse/asthma

Mouse/cystic fibrosis

Mouse/ischemia/reperfusion (I/R)

Mouse/cornea

Mouse/angiogenesis

Mouse/bone marrow transplant (BMT)

Rat/glomerulonephritis

Rat/hyperalgesia

Rat/pleuritis

Mouse/tumor growth

Mouse/allograft rejections

Mouse/arthritis

Rat/acute pancreatitis

Zebrafish/mycobacterial infection

Mouse/dorsal air pouch

Mouse/peritonitis

Rabbit/periodontitis

Mouse/retinopathy

Mouse/colitis

\section{Mechanism of action}

Inhibits neutrophil recruitment and vascular leakage

Inhibits neutrophil recruitment

Reduces PMN infiltration and prevents connective tissue and bone loss

Inhibits neutrophil recruitment and lymphatic removal of phagocytes

Attenuates pro-inflammatory gene expression and reduces severity of colitis, inhibits weight loss,

inflammation, and immune dysfunction

Inhibits airway hyper-responsiveness and pulmonary

inflammation

Decreases neutrophilic inflammation, pulmonary

bacterial burden, and disease severity

Attenuates hind limb I/R-induced lung injury.

Detachment of adherent leukocytes in mesenteric I/R

vessels. Reduces myocardial infarct size and area at risk in myocardial l/R

Accelerates cornea re-epithelialization, limits sequelae

of thermal injury (i.e., neovascularization, opacity) and

promotes host defense

Reduces angiogenic phenotype: endothelial cell

proliferation and migration

Protects against BMT-induced graft-versus-host diseases (GvHD)

Reduces leukocyte rolling and adherence; decreases neutrophil recruitment

Prolongs paw withdraw latency, reducing hyperalgesic

index, and reduces paw edema

Shortens the duration of pleural exudation

Suppresses the growth of transplanted tumors in mice; inhibits angiogenesis

Prevents acute rejection of vascularized cardiac and renal allografts

Inhibits edema formation and PMN influx, reduces

TNF $\alpha$ and $\mathrm{LTB}_{4}$ levels

Reduces intercellular adhesion molecule 1 (ICAM-1)

and NF-кB p65 expression in the pancreas, and

expression of ICAM-1 in the lungs

Reduces bacterial burden and growth; improves

microbial containment by phagocytes

Inhibits neutrophil recruitment

Inhibits neutrophil recruitment, regulates

chemokine/cytokine production, and promotes

lymphatic removal of phagocytes

Reduces PMN infiltration, prevents connective tissue and bone loss, promotes healing of diseased tissues, and promotes regeneration of lost soft tissue and bone

Protects against neovascularization

Decreases PMN recruitment and pro-inflammatory gene expression; improves survival and reduces weight loss; favors LPS-detoxification through induction of intestinal alkaline phosphatase

\section{Reference}

Takano et al. (1997)
Clish et al. (1999)
Serhan et al. (2003)

Bannenberg et al. (2005) and

Schwab et al. (2007)

Gewirtz et al. (2002)

Levy et al. (2002)

Karp et al. (2004)

Scalia et al. (1997) and Chiang et al. (1999)

Gronert et al. (2005)

Fierro et al. (2002)

Devchand et al. (2005)

Papayianni et al. (1995)

Svensson et al. (2007)

Bandeira-Melo et al. (2000)

Chen et al. (2010)

Levy et al. (2011)

Conte et al. (2010)

Zhou et al. (2011)

Tobin et al. (2012)

Serhan et al. (2000a)

Arita et al. (2005a),

Bannenberg et al. (2005), and

Schwab et al. (2007)

Hasturk et al. $(2006,2007)$

Connor et al. (2007)

Arita et al. (2005b), Campbell et al. (2010), and Ishida et al. (2010) 


\section{Table 1 | Continued}

\begin{tabular}{|c|c|c|c|}
\hline SPM & Disease model & Mechanism of action & Reference \\
\hline & Mouse/asthma & & \\
\hline & & in lungs to dampen airway inflammation; decreases & Haworth et al. (2008) \\
\hline & & eosinophil and lymphocyte recruitment & \\
\hline & Mouse/obesity & Regulates adipokines and protects against liver & Gonzalez-Periz et al. (2009) \\
\hline & & steatosis & \\
\hline & Mouse/inflammatory pain & Inhibits spontaneous pain, and heat and mechanical & Xu et al. (2010) \\
\hline & & hypersensitivity & \\
\hline & Rat/cardiac ischemia/reperfusion injury & Reduces infarct size & Keyes et al. (2010) \\
\hline & Mouse/allograft rejections & $\begin{array}{l}\text { Prevents acute rejection of vascularized cardiac and } \\
\text { renal allografts }\end{array}$ & Levy et al. (2011) \\
\hline & Mouse/dry eye & Promotes tear production, corneal epithelial & Li et al. (2010) \\
\hline & & integrity, and decreases in inflammatory inducible & \\
\hline & & COX-2. RvE1 inhibits keratocyte transformation to & \\
\hline & & myofibroblasts and lowers the number of & \\
\hline & & monocytes/macrophages & \\
\hline & Mouse/herpes simplex virus & Reduces severity of herpes simplex virus-induced & Rajasagi et al. (2011) \\
\hline & & ocular lesions, reduces angiogenesis, and stromal & \\
\hline & & keratitis & \\
\hline \multirow[t]{31}{*}{ Resolvin D1 } & Mouse/peritonitis & Inhibits neutrophil recruitment; shortens resolution & Hong et al. (2003), Sun et al. \\
\hline & & interval; regulates miRNAs and target genes in & (2007), Spite et al. (2009b), \\
\hline & & resolving exudates; reduces $\mathrm{LTB}_{4}, \mathrm{PGD}_{2}, \mathrm{PGF} 2_{\alpha}$ & Recchiuti et al. (2011), \\
\hline & & and $\mathrm{TXA}_{2}$ in peritoneal exudates & Krishnamoorthy et al. (2012), \\
\hline & & & and Norling et al. (2012) \\
\hline & Mouse/E. coli (peritoneal) and & Reduces bacterial titers and hypothermia; increased & Chiang et al. (2012) \\
\hline & S. aureus (skin) infection & survival; enhances microbial containment and killing & \\
\hline & & by phagocytes; lowers antibiotic requirement; & \\
\hline & & shortens resolution interval & \\
\hline & Mouse/dorsal air pouch & Inhibits neutrophil recruitment & Serhan et al. (2002) and Hong \\
\hline & & & et al. (2003) \\
\hline & Mouse/kidney ischemia-reperfusion & Protects from ischemia/reperfusion-induced kidney & Duffield et al. (2006) \\
\hline & & damage and loss of function; regulates macrophages & \\
\hline & Mouse/retinopathy & Protects against neovascularization & Connor et al. (2007) \\
\hline & Mouse/inflammatory pain & Inhibits spontaneous pain, heat, and mechanical & Xu et al. (2010) and Park et al. \\
\hline & & hypersensitivity; selectively blocks TRPV1 and & $(2011)$ \\
\hline & & TRPA1-mediated pain & \\
\hline & Mouse/obesity & Reduces inflammatory cytokines in adipose tissue & Titos et al. (2011) \\
\hline & & macrophages; stimulates M2 macrophage & \\
\hline & & differentiation; promotes resolution of adipose tissue & \\
\hline & & inflammation & \\
\hline & Mouse/T2 diabetes & Reduces macrophage accumulation in adipose & Hellmann et al. (2011) \\
\hline & & tissue; ameliorates insulin sensitivity & \\
\hline & Rats/post-operative pain & Reduces post-operative pain, tactile allodynia, and & Huang et al. (2011) \\
\hline & & hyperalgesia & \\
\hline & Mouse/pain & Attenuates agonist-induced and inflammatory pain & Bang et al. (2010) and Xu et al. \\
\hline & & behaviors; inhibits TRPA1, TRPV3, and TRPV4 & $(2010)$ \\
\hline & & receptors; does not affect basal sensitivity & \\
\hline & Mouse/acute lung injury & Blocks leukocyte infiltration and reduces cytokine & Wang et al. (2011) \\
\hline & & levels in BALF & \\
\hline & Mouse/corneal inflammation & Reduces leukocyte infiltration and hemangiogenesis & Jin et al. (2009) \\
\hline
\end{tabular}


Table 1 | Continued

\begin{tabular}{|c|c|c|c|}
\hline SPM & Disease model & Mechanism of action & Reference \\
\hline \multirow[t]{3}{*}{ AT-RvD1 } & Mouse/colitis & $\begin{array}{l}\text { Reduces disease activity index, PMN number, and } \\
\text { pro-inflammatory levels }\end{array}$ & Bento et al. (2011) \\
\hline & & $\begin{array}{l}\text { Attenuates pain signals and behaviors by blocking } \\
\text { TRPV3 }\end{array}$ & Bang et al. (2012) \\
\hline & Rats/arthritic pain & $\begin{array}{l}\text { Possesses anti-hyperalgesic effects upon systemic } \\
\text { administration. Decreases TNF- } \alpha \text { and IL-1 } \beta \text { production }\end{array}$ & Lima-Garcia et al. (2011) \\
\hline \multirow[t]{3}{*}{ Resolvin D2 } & Mouse/peritonitis & Blocks further PMN infiltration into the peritoneum & Spite et al. (2009a) \\
\hline & Mouse/sepsis & $\begin{array}{l}\text { Prevents hypothermia, decreases bacterial load in the } \\
\text { blood and peritoneum, promotes survival }\end{array}$ & Spite et al. (2009a) \\
\hline & Mouse/colitis & $\begin{array}{l}\text { Improves disease activity index, weight loss, and } \\
\text { colonic PMN infiltration. Reduces pro-inflammatory } \\
\text { levels }\end{array}$ & Bento et al. (2011) \\
\hline \multirow[t]{9}{*}{ (Neuro)Protectin D1 } & Mouse/peritonitis & $\begin{array}{l}\text { Inhibits neutrophil recruitment and regulates } \\
\text { chemokine/cytokine production } \\
\text { Promotes lymphatic removal of phagocytes; regulates } \\
\text { T-cell migration; enhances CCR5 expression on } \\
\text { apoptotic leukocytes }\end{array}$ & $\begin{array}{l}\text { Bannenberg et al. (2005) and } \\
\text { Serhan et al. (2006) } \\
\text { Ariel et al. (2005, 2006) and } \\
\text { Schwab et al. (2007) }\end{array}$ \\
\hline & Mouse/asthma & $\begin{array}{l}\text { Protects from lung damage, airway inflammation, and } \\
\text { hyper-responsiveness }\end{array}$ & Levy et al. (2007) \\
\hline & Human/asthma & PD1 is generated in human asthmatic patients & Levy et al. (2007) \\
\hline & Mouse/kidney ischemia/reperfusion & $\begin{array}{l}\text { Protects from ischemia/reperfusion-induced kidney } \\
\text { damage and loss of function; regulates macrophages }\end{array}$ & Duffield et al. (2006) \\
\hline & Mouse/retinopathy & Protects against neovascularization & Connor et al. (2007) \\
\hline & Rat/ischemic stroke & $\begin{array}{l}\text { Inhibits leukocyte infiltration, NF-кB, and COX-2 } \\
\text { induction }\end{array}$ & Marcheselli et al. (2003) \\
\hline & Human/Alzheimer's disease & $\begin{array}{l}\text { Diminished PD1 production in human Alzheimer's } \\
\text { disease }\end{array}$ & Lukiw and Bazan (2008) \\
\hline & Mouse/liver injury & Protects from necroinflammatory liver injury & Gonzalez-Periz et al. (2009) \\
\hline & Mouse/Alzheimer's disease & $\begin{array}{l}\text { Downregulates inflammatory genes; reduces } \\
\text { amyloidogenic A } \beta 42 \text { cleavage; protects from } \\
\text { apoptosis }\end{array}$ & Zhao et al. (2011) \\
\hline \multirow[t]{3}{*}{ Maresin-1 } & Mouse/peritonitis & Blocks PMN infiltration into the peritoneum & Serhan et al. (2009) \\
\hline & Planaria/tissue regeneration & Stimulates tissue regeneration post surgical damage & Serhan et al. (2012) \\
\hline & Mouse/pain & Reduces pain & Serhan et al. (2012) \\
\hline
\end{tabular}

monitor temporal changes in both leukocyte numbers and composition. Rapidly after zymosan injection, leukocytes infiltrated the peritoneal cavity during the onset phase of acute inflammation $(4 \mathrm{~h})$, reaching a maximum $\left(\sim 22.0 \times 10^{6}\right)$ at $\sim 12 \mathrm{~h}$ and declined at $24-48 \mathrm{~h}$. Differential analysis with flow cytometry confirmed that the majority of leukocytes in exudates at 4 and $12 \mathrm{~h}$ were PMN (Ly-6Ghigh/CD11b ${ }^{+} ; \sim 10.0 \times 10^{6}$ cells at $4 \mathrm{~h}$ and $\sim 15 \times 10^{6}$ cells at $12 \mathrm{~h}$ ). PMN number declined during the resolution phase 24 and $48 \mathrm{~h}$ after initiation of peritonitis. Conversely, resident peritoneal $\mathrm{M} \Phi \mathrm{s}$ (F4/80+cells), which represent the main leukocyte population in naive mice peritonea (Winyard and Willoughby, 2003), were not detected in exudates at $4 \mathrm{~h}$. Monocytes (Ly-6G ${ }^{\text {low/ }} \mathrm{CD} 11 \mathrm{~b}^{\text {high }}$ cells) gradually increased at $12 \mathrm{~h}$ and differentiated into $\mathrm{M} \Phi \mathrm{s}$, consistent with their pro-resolution functions (Gordon, 2007), reaching 60\% of exudate leukocytes at $48 \mathrm{~h}$. Because it is important to define resolution in unbiased terms, resolution indices, introduced by Bannenberg et al. (2005), were calculated (i.e., $\Psi_{\max } \sim 15.0 \times 10^{6}$; $T_{\max } \sim 12 \mathrm{~h}$; $\Psi_{50} \sim 7.5 \times 10^{6}$; $T_{50} \sim 30 \mathrm{~h} ; R_{\mathrm{i}} \sim 18 \mathrm{~h}$; Figure 7$)$ to characterize the resolution phase and determine temporal changes in miRNA expression during this time interval. Hierarchical clustering grouped the $\sim 300$ miRNAs examined into distinct clusters based on their relative abundance at the different time intervals, indicating that specific miRNAs are temporally regulated during acute inflammation and its natural self-limited resolution.

In these studies, miR-21, miR-146b, miR-208a, and miR-219 were significantly regulated at 12 and $24 \mathrm{~h}$ compared to $4 \mathrm{~h}$ (Figure 7), suggesting a role in resolution. For instance, miR-21 proved to be critical for the production of anti-inflammatory IL-10 in experimental peritonitis (Sheedy et al., 2010), corroborating our findings. Next, resolution indices were used to pinpoint RvD1 actions in resolution. RvD1, administered in its pro-drug carboxy 


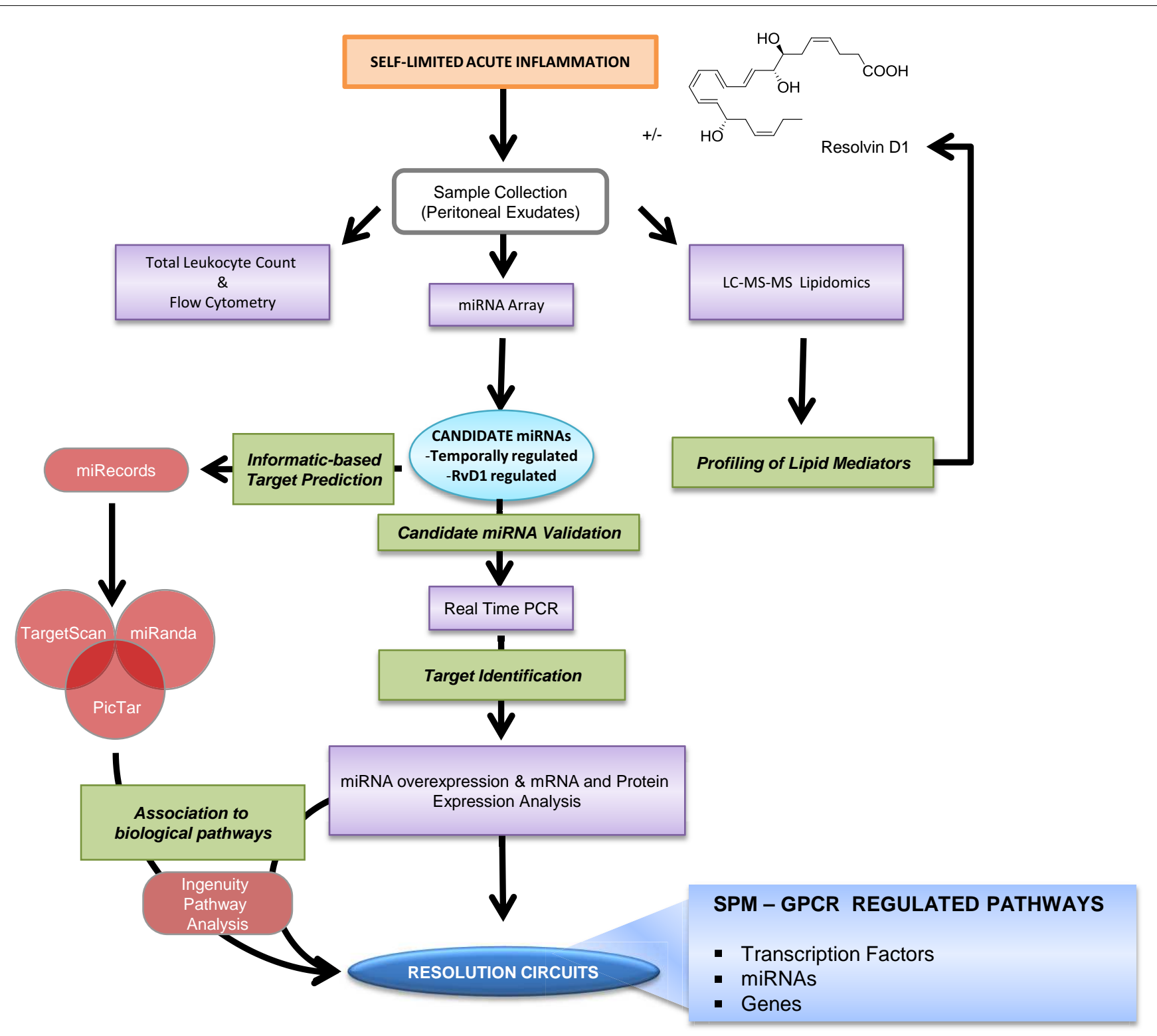

FIGURE 6 | Strategy for identification of RvD1-GPCR circuits. Self-limited zymosan-stimulated mouse peritonitis was used to obtain resolving exudates that were collected 4, 12, 24, and $48 \mathrm{~h}$ after zymosan A injection for temporal and differential analysis of leukocyte counts and phenotype, miRNA real-time PCR analysis, and lipidomics as in Recchiuti et al. (2011) and Krishnamoorthy et al. (2012). Candidate miRNAs, defined as those that were temporally and/or RvD1-regulated, were confirmed using bioinformatics and prediction of target genes, real-time PCR, as well as overexpression in human MФs. The Ingenuity Pathway Analysis Software database was used to identify circuits of molecules and biological functions controlled by RvD1-regulated miRNAs and target genes (see text; Recchiuti et al., 2011 for analysis details). methyl ester form, significantly lowered the $\Psi_{\max }$ (from 15.0 to $11.5 \times 10^{6}$ ), and accelerated or shortened the $R_{\mathrm{i}}$ by $\sim 4 \mathrm{~h}$. Quantitative real-time PCR analyses carried out with exudates from zymosan- and zymosan plus RvD1-treated mice revealed that RvD1 temporally controls the specific sets of pro-resolving miRNAs miR-21, miR-146b, miR-208a, and miR-219 (coined resolution $m i R s)$ in exudates in vivo. For translation to humans, actions of RvD1 on these miRNAs were assessed in ALX/FPR2 and DRV1/GPR32-overexpressing isolated human cells, namely $M \Phi$, the master regulators of resolution. Notably, RvD1 also regulated
miR-21, -146b, -208a, and 219 in a GPCR-dependent manner. In order to identify target molecules of RvD1-GPCR-regulated miRs, we overexpressed miR-146b, -208a, and -219 in human M $\Phi$ for real-time PCR analysis to assess which mRNAs were significantly regulated.

Since miRNAs can regulate mRNAs and protein levels of hundreds of genes involved in biological processes (Bartel, 2009), miR-target genes were clustered using the Ingenuity Pathway Analysis knowledge database based on their physical and/or functional interactions, creating the first identified 


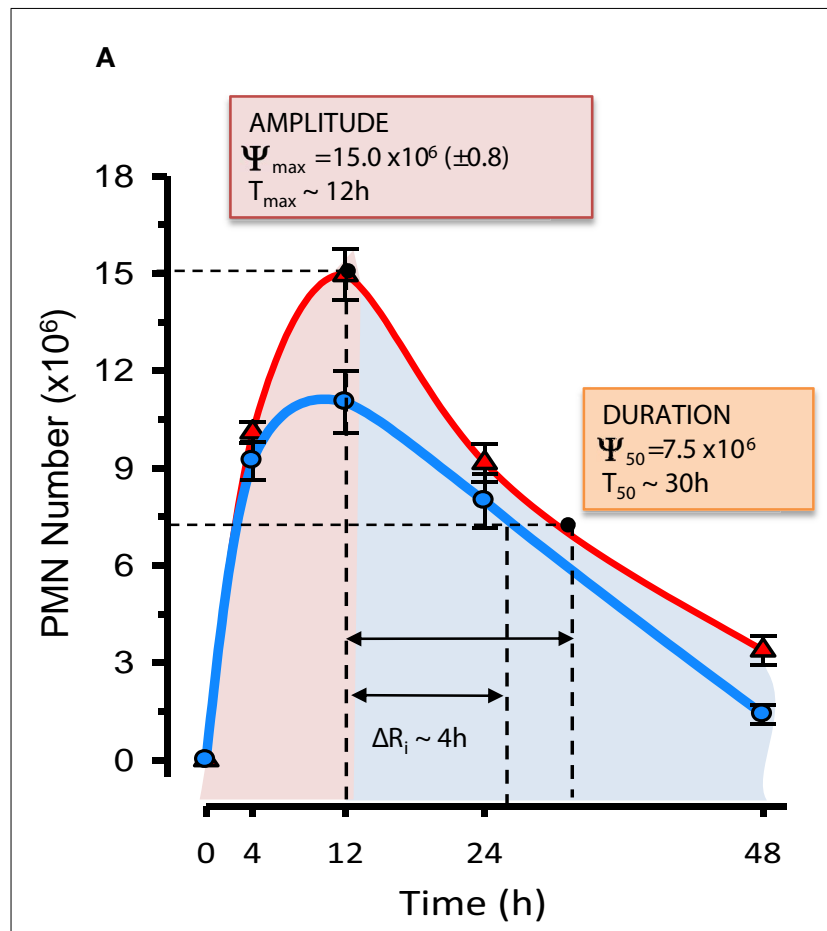

FIGURE 7 | Resolution indices and miRNA signature of resolution. (A) Resolution indices were calculated as in (Bannenberg et al., 2005) using PMN numbers in peritoneal exudates from mice treated with zymosan alone (red line) and zymosan plus RvD1 (blue line) at indicated time intervals: $T_{\max }$, time of maximum PMN infiltration $\left(\Psi_{\max }\right) ; T_{50}$, time to achieve $50 \%$ reduction in PMN number $\left(\Psi_{50}\right)$ from $\Psi_{\max } ; R_{\mathrm{i}}$, resolution interval $\left(T_{50}-T_{\max } ;\right.$ time interval between $T_{\max }$ and $T_{50}$ ). RvD1, administered at the beginning of peritonitis,
B

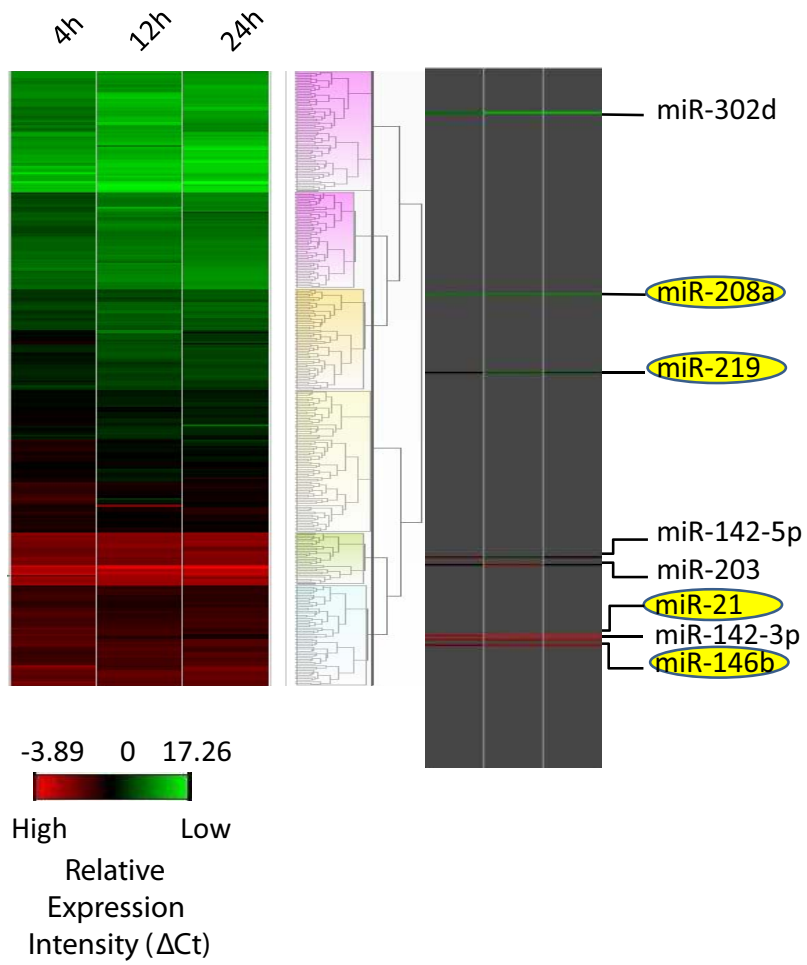

significantly lowers amplitude (i.e., $\left.\Psi_{\max }\right)$ and duration $\left(T_{50}\right)$ of PMN infiltration, shortening the $R_{\mathrm{i}}$ by $\sim 4 \mathrm{~h}$. (B) Heat map cluster represents relative expression of $\sim 300$ mouse miRNAs from resolving exudates determined with real-time PCR after normalization with housekeeping small RNAs (snoRNA251, snoRNA202, snoRNA142, and Rnu6). Relative expression intensities are indicated in a green-red color code based on $\Delta$ Ct expression values $(n=3$ mice/group). Temporal and RvD1-regulated miRNAs are highlighted.
RvD1-GPCR-regulated gene networks involved in inflammation and resolution. For instance, miR-146 networks 1 and 3 included genes of the NF- $\kappa \mathrm{B}$ activation pathway (e.g., I $\kappa \mathrm{B}$ kinase and tumor necrosis factor receptor-associated factor 6) and innate response to pathogens (e.g., Toll-like receptors, S100 protein, Creactive protein, peptidoglycan recognition protein; Figure 8A). Several cytokines and chemokines (IL-8, 10, 12, interferon- $\alpha$ and $\beta$ ) belonged to the miR-146b network 2 (Figure $8 \mathrm{~A}$ ). NF- $\kappa \mathrm{B}$ is a critical transcription factor involved in regulation of cell functions in inflammation and resolution (Lawrence et al., 2001). Of interest, RvD1 in human monocytes reduces the nuclear translocation of NF- $\kappa$ B, TNF- $\alpha$ induced phosphorylation of I $\kappa$ B (Recchiuti et al., 2011), counteracts NF- $\kappa B$ activation in ALX/FPR2 and DRV1/GPR32 recombinant cells (Krishnamoorthy et al., 2010), dampens acute inflammation in murine dorsal air pouches evoked by local administration of TNF- $\alpha$ (Serhan et al., 2002), and downregulates IKK levels in murine peritonitis (Recchiuti et al., 2011). Therefore, regulation of miRNAs and the TNF- $\alpha-N F-\kappa B$ axis seems to be a key component in the RvD1-GPCR downstream signaling network.

The miRNA miR-208a downregulates CD14, CD40 ligand, PGI2 receptor, thromboxane A2 receptor, and programmed cell death (Recchiuti et al., 2011; Figure 8B), a tumor suppressor molecule that acts as a translational repressor of IL-10 (Sheedy et al., 2010), consistent with the existence of a seed region for miR$208 \mathrm{a}$ in the $3^{\prime}$ UTR of PDCD4. Notably, in self-limited peritonitis, RvD1 reduced PDCD4 and increased IL-10 production, providing in vivo correlates of $\mathrm{RvD1}$-miR-dependent gene regulations.

The miR-219 network includes CD14 and 5-LO (Figure 8C), a key enzyme for the biosynthesis of LTs, and SPMs. In addition, a significant reduction in 5-LO protein levels and $\mathrm{LTB}_{4}$ production was found in human $\mathrm{M} \Phi$ overexpressing the RvD1-regulated miR219 , translating findings in mouse peritonitis to the human M $\Phi$ cell system (Recchiuti et al., 2011). Endogenous regulatory mechanisms of 5-LO are of wide interest given the important roles of LTs, LXs, and Rvs in inflammation and resolution (Samuelsson, 1983; Serhan et al., 2002). In addition to transcriptional regulation by cytokines and growth factors (Radmark et al., 2007), miR-219 can provide a rapid mean to balance the abundance of 5 -LO protein in cells under dynamic conditions such as during inflammation.

RvD1 actions were also tested in genetically engineered mice in order to obtain further evidence of ALX/FPR2-dependent action. Transgenic mouse colonies in which human ALX/FPR2 gene was placed under control of a CD11b promoter that drives transgene expression in mature murine myeloid cells were created 
A

miR-146b Network 1

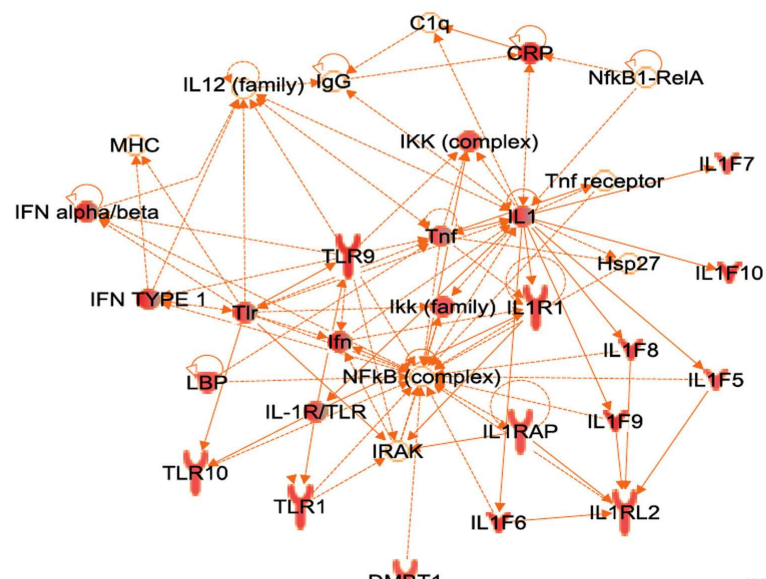

miR-146b Network 2

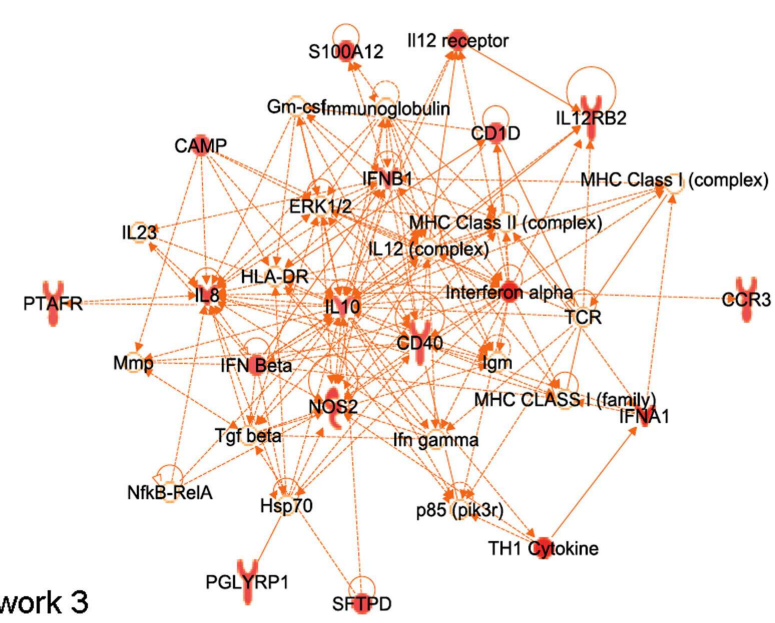

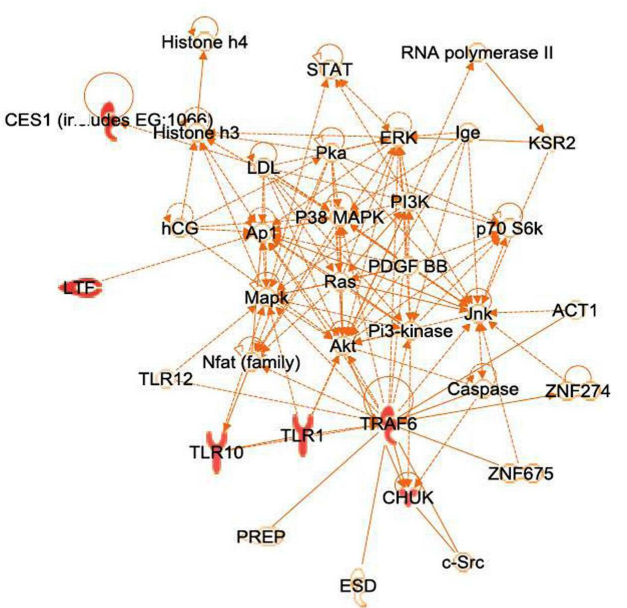

B

miR-208a Network

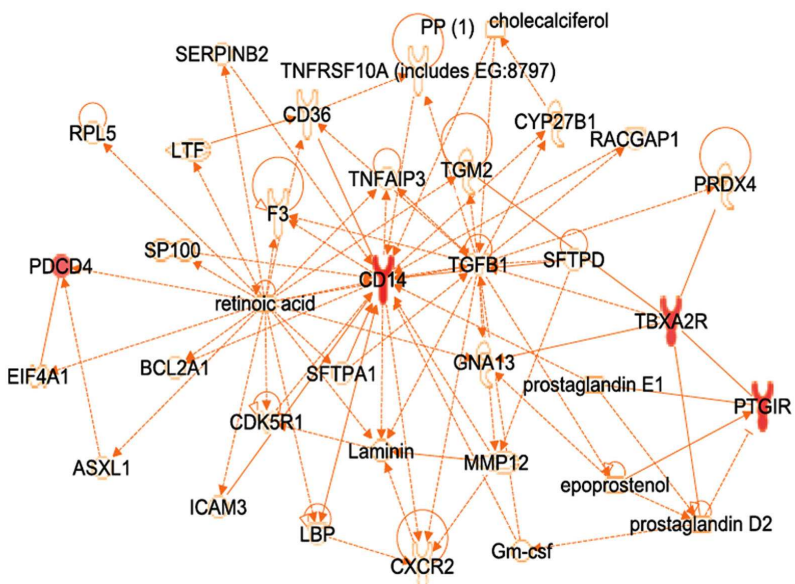

C

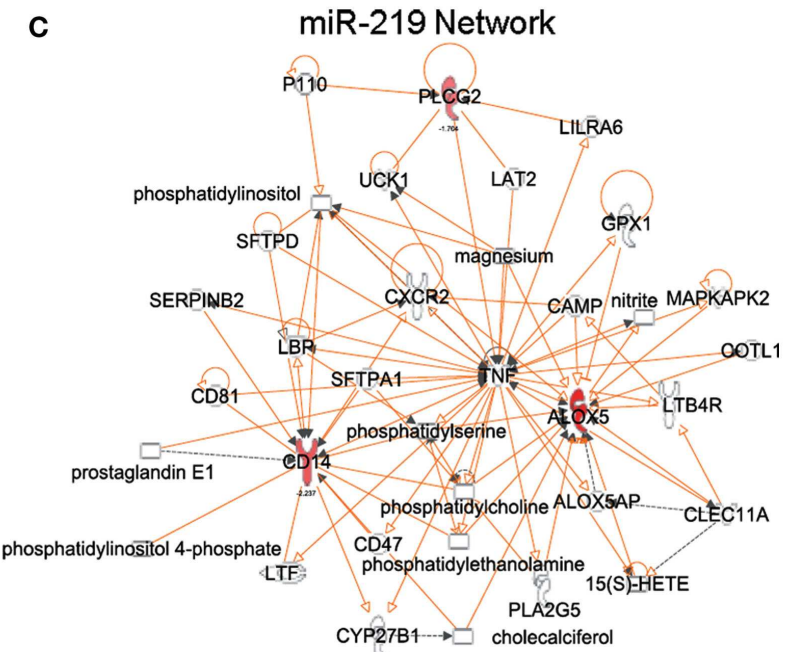

FIGURE 8 | Translation of RvD1-dependent miRNA circuits in human cells. RvD1-GPCR gene networks connecting target genes of miR-146b (A), miR-208a (B), and miR-219 (C). Genes that are significantly down regulated in each network are indicated in red. 


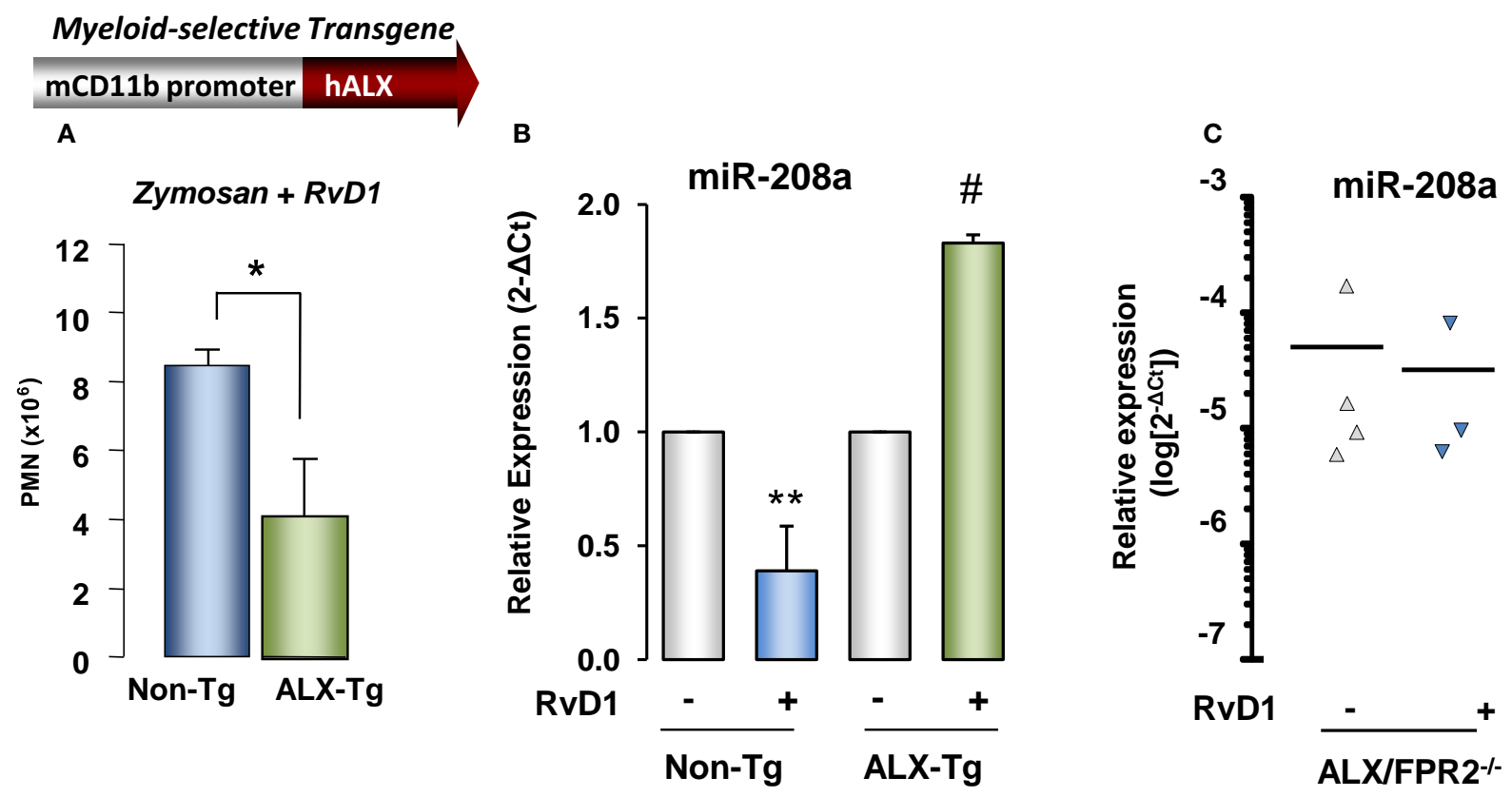

FIGURE 9 | Evidence for ALX/FPR2-RvD1-dependent miRNA pathways in vivo. Reduction in (A) PMN infiltration by RvD1 is significantly higher in myeloid-driven human ALX-transgenic ( $\mathrm{Tg}$ ) mice challenged with zymosan ( $1 \mathrm{mg} /$ mouse, i.p., $24 \mathrm{~h}$ ) than non-Tg littermates. Results are mean \pm SEM from three mice/group $\left({ }^{*} P<0.05\right.$ vs. non-Tg). (B) Relative expression of miR-208a determined in resolving exudates $24 \mathrm{~h}$ after zymosan alone or zymosan plus RvD1 administration in hALX-Tg or non-Tg littermates (mean \pm SEM, $n=3$ mice/group; ** $P<0.05$ vs. non-Tg zymosan group; \#, $P<0.05$ vs. hALX-Tg zymosan group). (C) miR-208a expression in peritoneal exudates $(24 \mathrm{~h})$ from ALX/FPR2 knockout mice treated with zymosan alone or zymosan plus RvD1.
(Devchand et al., 2003). Interestingly, total peritoneal leukocytes at $24 \mathrm{~h}$ peritonitis were significantly lower in ALX/FPR2 transgenic mice treated with zymosan alone compared to non-transgenic littermates, and RvD1 administration resulted in a further significant decrease ( $\sim 53 \%$ reduction) in peritoneal exudate leukocyte numbers in ALX/FPR2 transgenic mice compared to non-transgenic littermates (Figure 9). Quantitative PCR analysis of miRNAs isolated from peritoneal lavages collected $24 \mathrm{~h}$ post injection of zymosan showed that RvD1 significantly upregulated identified resolution miRs miR-208a and miR-219 in vivo (Recchiuti et al., 2011), whereas it does not appear to regulate miR-21, miR-146b, and miR-302d (Figure 9). To further investigate ALX/FPR2dependent actions of RvD1 in vivo, it was next tested whether RvD1 can regulate some of these miRNAs in ALX/FPR2 knockout mice, where $\mathrm{LXA}_{4}$ did not regulate leukocyte trafficking (Dufton et al., 2010). In ALX/FPR2 ${ }^{-/-}$mice, RvD1 did not regulate PMN infiltration, consistent with recent results (Norling et al., 2012), nor did it significantly alter miR-208a or miR-219 expression at $24 \mathrm{~h}$ (Figure 9).

Taken together, these results indicate that RvD1 controls leukocyte infiltration and specific resolution phase miRs in acute inflammation in an ALX/FPR2-dependent manner in mice and DRV1/GPR32-dependent in isolated human cells.

\section{SUMMATION AND CONCLUSION}

It is now eminently clear that the acute inflammatory response of the host is a highly coordinated defensive response and its complete resolution is the ideal outcome. This ideal outcome is achieved in self-limited inflammation by activation of endogenous resolution programs that are governed in part by resolution phase local chemical mediators. Excessive inflammation can lead to chronic disorders and host damage. LM from AA, such as PGs and LTs, can amplify the inflammatory response, and $\mathrm{PGE}_{2}$ and $\mathrm{D}_{2}$ initiate the "class switch" that leads to the biosynthesis of $\mathrm{LXA}_{4}$, the first member of the new genus of SPM. SPM include several families of LM such as E-and D-series Rv (neuro)PD, and the youngest family, the MaR, which are biosynthesized from essential $\omega-3$ fatty acids. Of interest in experimental animal models of disease, each of the SPM can accelerate the resolution process when administered in vivo, and their bioactions are highly stereospecific, GPCR-mediated, and exerted at low doses. SPM also reduce pain and promote tissue regeneration, the ultimate goal of complete return to homeostasis. Results from the first human clinical Phase I and II trial with a Rv analog appear encouraging and can open new opportunities for resolution pharmacology based on endogenous mediators to terminate inflammation and treat inflammation-related diseases. We trust that more human trials will be launched to test the notion that stimulating resolution mechanisms can improve disease and health status.

\section{ACKNOWLEDGMENT}

This work was supported by National Institutes of Health grant no. R01-GM038765. 


\section{REFERENCES}

Abbas, A. K., Lichtman, A. H., and Pillai, S. (2011). Cellular and Molecular Immunology, 7th Edn. Philadelphia: Elsevier Saunders.

Alam, M. M., and O'Neill, L. A. (2011). MicroRNAs and the resolution phase of inflammation in macrophages. Eur. J. Immunol. 41, 2482-2485.

Aoki, H., Hisada, T., Ishizuka, T., Utsugi, M., Kawata, T., Shimizu, Y., Okajima, F., Dobashi, K., and Mori, M. (2008). Resolvin E1 dampens airway inflammation and hyperresponsiveness in a murine model of asthma. Biochem. Biophys. Res. Commun. 367, 509-515.

Aoki, H., Hisada, T., Ishizuka, T., Utsugi, M., Ono, A., Koga, Y., Sunaga, N., Nakakura, T., Okajima, F., Dobashi, K., and Mori, M. (2010). Protective effect of resolvin E1 on the development of asthmatic airway inflammation. Biochem. Biophys. Res. Commun. 400, 128-133.

Ariel, A., Fredman, G., Sun, Y.-P., Kantarci, A., Van Dyke, T. E., Luster, A. D., and Serhan, C. N. (2006). Apoptotic neutrophils and $\mathrm{T}$ cells sequester chemokines during immune response resolution through modulation of CCR5 expression. Nat. Immunol. 7, 1209-1216.

Ariel, A., Li, P.-L., Wang, W., Tang, W.X., Fredman, G., Hong, S., Gotlinger, K. H., and Serhan, C. N. (2005). The docosatriene protectin D1 is produced by $\mathrm{TH} 2$ skewing and promotes human $\mathrm{T}$ cell apoptosis via lipid raft clustering. J. Biol. Chem. 280, 43079-43086.

Arita, M., Bianchini, F., Aliberti, J., Sher, A., Chiang, N., Hong, S., Yang, R., Petasis, N. A., and Serhan, C. N. (2005a). Stereochemical assignment, antiinflammatory properties, and receptor for the omega-3 lipid mediator resolvin E1. J. Exp. Med. 201, 713-722.

Arita, M., Yoshida, M., Hong, S., Tjonahen, E., Glickman, J. N., Petasis, N. A., Blumberg, R. S., and Serhan, C. N. (2005b). Resolvin $\mathrm{E} 1$, an endogenous lipid mediator derived from omega-3 eicosapentaenoic acid, protects against 2,4,6-trinitrobenzene sulfonic acidinduced colitis. Proc. Natl. Acad. Sci. U.S.A. 102, 7671-7676.

Arita, M., Ohira, T., Sun, Y.-P., Elangovan, S., Chiang, N., and Serhan, C. N. (2007). Resolvin E1 selectively interacts with leukotriene B4 receptor BLT1 and ChemR23 to regulate inflammation. J. Immunol. 178, 3912-3917.
Bandeira-Melo, C., Serra, M. F., Diaz, B. L., Cordeiro, R. S., Silva, P. M., Lenzi, H. L., Bakhle, Y. S., Serhan, C. N., and Martins, M. A. (2000). Cyclooxygenase2-derived prostaglandin E2 and lipoxin A4 accelerate resolution of allergic edema in Angiostrongylus costaricensis-infected rats: relationship with concurrent eosinophilia. J. Immunol. 164, 1029-1036.

Bang, S., Yoo, S., Yang, T. J., Cho, H., and Hwang, S. (2012). 17(R)-resolvin D1 specifically inhibits TRPV3 leading to peripheral antinociception. $\mathrm{Br}$. J. Pharmacol. 165, 683-692.

Bang, S., Yoo, S., Yang, T. J., Cho, H., Kim, Y. G., and Hwang, S. W. (2010). Resolvin D1 attenuates activation of sensory transient receptor potential channels leading to multiple antinociception. Br. J. Pharmacol. 161, 707-720.

Bannenberg, G., and Serhan, C. N. (2010). Specialized pro-resolving lipid mediators in the inflammatory response: an update. Biochim. Biophys. Acta 1801, 1260-1273.

Bannenberg, G. L., Chiang, N., Ariel, A., Arita, M., Tjonahen, E., Gotlinger, K. H., Hong, S., and Serhan, C. N. (2005). Molecular circuits of resolution: formation and actions of resolvins and protectins. J. Immunol. 174, 4345-4355.

Bartel, D. P. (2009). MicroRNAs: target recognition and regulatory functions. Cell 136, 215-233.

Bazan, N. G. (2007). Homeostatic regulation of photoreceptor cell integrity: significance of the potent mediator neuroprotectin D1 biosynthesized from docosahexaenoic acid: the Proctor Lecture. Invest. Ophthalmol. Vis. Sci. 48, 4866-4881; biography 4864-4865.

Bento, A. F., Claudino, R. F., Dutra, R. C., Marcon, R., and Calixto, J. B. (2011). Omega-3 fatty acidderived mediators 17(R)-hydroxy docosahexaenoic acid, aspirintriggered resolvin D1 and resolvin D2 prevent experimental colitis in mice. J. Immunol. 187, 1957-1969.

Brink, C., Dahlen, S. E., Drazen, J., Evans, J. F., Hay, D. W., Nicosia, S., Serhan, C. N., Shimizu, T., and Yokomizo, T. (2003). International Union of Pharmacology XXXVII. Nomenclature for leukotriene and lipoxin receptors. Pharmacol. Rev. 55, 195-227.

Burr, G. O., and Burr, M. M. (1929). A new deficiency disease produced by the rigid exclusion of fat from the diet. J. Biol. Chem. 82, 345-367.
Calder, P. C. (2009). Polyunsaturated fatty acids and inflammatory processes: New twists in an old tale. Biochimie 91, 791-795.

Campbell, E. L., MacManus, C. F., Kominsky, D. J., Keely, S., Glover, L. E., Bowers, B. E., Scully, M., Bruyninckx, W. J., and Colgan, S. P. (2010). Resolvin E1-induced intestinal alkaline phosphatase promotes resolution of inflammation through LPS detoxification. Proc. Natl. Acad. Sci. U.S.A. 107, 14298-14303.

Chan, M. M., and Moore, A. R. (2010). Resolution of inflammation in murine autoimmune arthritis is disrupted by cyclooxygenase- 2 inhibition and restored by prostaglandin E2-mediated lipoxin A4 production. J. Immunol. 184, 6418-6426.

Chen, Y., Hao, H., He, S., Cai, L., Li, Y. $\mathrm{Hu}, \mathrm{S}$., Ye, D., Hoidal, J., Wu, P., and Chen, X. (2010). Lipoxin A4 and its analogue suppress the tumor growth of transplanted $\mathrm{H} 22$ in mice: the role of antiangiogenesis. Mol. Cancer Ther. 9, 2164-2174

Chiang, N., Bermudez, E. A., Ridker, P. M., Hurwitz, S., and Serhan, C. N. (2004). Aspirin triggers antiinflammatory 15-epi-lipoxin A4 and inhibits thromboxane in a randomized human trial. Proc. Natl. Acad. Sci. U.S.A. 101, 15178-15183.

Chiang, N., Fredman, G., Bäckhed, F., Oh, S. F., Vickery, T. W., Schmidt, B. A., and Serhan, C. N. (2012). Infection regulates proresolving mediators that lower antibiotic requirements. Nature 484 524-528.

Chiang, N., Gronert, K., Clish, C. B. O'Brien, J. A., Freeman, M. W., and Serhan, C. N. (1999). Leukotriene B4 receptor transgenic mice reveal novel protective roles for lipoxins and aspirin-triggered lipoxins in reperfusion. J. Clin. Invest. 104 309-316.

Chiang, N., Serhan, C. N., Dahlen, S. E., Drazen, J. M., Hay, D. W., Rovati, G. E., Shimizu, T., Yokomizo, T., and Brink, C. (2006). The lipoxin receptor ALX: potent ligand-specific and stereoselective actions in vivo. Pharmacol. Rev. 58, 463-487.

Chiang, N., Takano, T., Arita, M., Watanabe, S., and Serhan, C. N. (2003). A novel rat lipoxin A4 receptor that is conserved in structure and function. Br. J. Pharmacol. 139, 89-98.

Claria, J., and Serhan, C. N. (1995). Aspirin triggers previously undescribed bioactive eicosanoids by human endothelial cell-leukocyte interactions. Proc. Natl. Acad. Sci. U.S.A. 92, 9475-9479.
Clish, C. B., O’Brien, J. A., Gronert, K., Stahl, G. L., Petasis, N. A., and Serhan, C. N. (1999). Local and systemic delivery of a stable aspirin-triggered lipoxin prevents neutrophil recruitment in vivo. Proc. Natl. Acad. Sci. U.S.A. 96, 8247-8252.

Connor, K. M., Sangiovanni, J. P., Lofqvist, C., Aderman, C. M., Chen, J., Higuchi, A., Hong, S., Pravda, E. A., Majchrzak, S., Carper, D., Hellstrom, A., Kang, J. X., Chew, E. Y., Salem, N., Serhan, C. N., and Smith, L. E. H. (2007). Increased dietary intake of omega-3-polyunsaturated fatty acids reduces pathological retinal angiogenesis. Nat. Med. 13, 868-873.

Conte, F. P., Menezes-De-Lima, O., Verri, W. A., Cunha, F. Q., Penido, C., and Henriques, M. G. (2010). Lipoxin A(4) attenuates zymosaninduced arthritis by modulating endothelin-1 and its effects. $B r$. $J$ Pharmacol. 161, 911-924.

Dalli, J., Norling, L. V., Renshaw, D., Cooper, D., Leung, K. Y., and Perretti, M. (2008). Annexin 1 mediates the rapid anti-inflammatory effects of neutrophil-derived microparticles. Blood 112, 2512-2519.

De Caterina, R. (2011). n-3 fatty acids in cardiovascular disease. N. Engl. J. Med. 364, 2439-2450.

Devchand, P. R., Arita, M., Hong, S., Bannenberg, G., Moussignac, R. L., Gronert, K., and Serhan, C. N. (2003). Human ALX receptor regulates neutrophil recruitment in transgenic mice: roles in inflammation and host defense. FASEB J. 17, 652-659.

Devchand, P. R., Schmidt, B. A., Primo, V. C., Zhang, Q.-Y., Arnaout, M. A., Serhan, C. N., and Nikolic, B. (2005). A synthetic eicosanoid LXmimetic unravels host-donor interactions in allogeneic BMT-induced GvHD to reveal an early protective role for host neutrophils. FASEB J. 19, 203-210.

Dona, M., Fredman, G., Schwab, J. M., Chiang, N., Arita, M., Goodarzi, A., Cheng, G., Von Andrian, U. H., and Serhan, C. N. (2008). Resolvin E1, an EPA-derived mediator in whole blood, selectively counterregulates leukocytes and platelets. Blood 112, 848-855.

Duffield, J. S., Hong, S., Vaidya, V. S., Lu, Y., Fredman, G., Serhan, C. N., and Bonventre, J. V. (2006). Resolvin $\mathrm{D}$ series and protectin D1 mitigate acute kidney injury. J. Immunol. 177, 5902-5911.

Dufton, N., Hannon, R., Brancaleone, V., Dalli, J., Patel, H. B., Gray, M., D’Acquisto, F., Buckingham, J. 
C., Perretti, M., and Flower, R. J. (2010). Anti-inflammatory role of the murine formyl-peptide receptor 2: ligand-specific effects on leukocyte responses and experimental inflammation. J. Immunol. 184, 2611-2619.

Edenius, C., Kumlin, M., Bjork, T., Anggard, A., and Lindgren, J. A. (1990). Lipoxin formation in human nasal polyps and bronchial tissue. FEBS Lett. 272, 25-28.

Fierro, I. M., Kutok, J. L., and Serhan, C. N. (2002). Novel lipid mediator regulators of endothelial cell proliferation and migration: aspirin-triggered-15R-lipoxin $\mathrm{A}(4)$ and lipoxin A(4). J. Pharmacol. Exp. Ther. 300, 385-392.

Fiore, S., Brezinski, M. E., Sheppard, K. A., and Serhan, C. N. (1991). The lipoxin biosynthetic circuit and their actions with human neutrophils. Adv. Exp. Med. Biol. 314, 109-132.

Fiore, S., Maddox, J. F., Perez, H. D., and Serhan, C. N. (1994). Identification of a human cDNA encoding a functional high affinity lipoxin A4 receptor. J. Exp. Med. 180, 253-260.

Fiore, S., Ryeom, S. W., Weller, P. F., and Serhan, C. N. (1992). Lipoxin recognition sites. Specific binding of labeled lipoxin A4 with human neutrophils. J. Biol. Chem. 267, 16168-16176.

Flower, R. J. (2006). Prostaglandins, bioassay and inflammation. Br. J. Pharmacol. 147(Suppl. 1), S182S192.

Fredman, G., Oh, S. F., Ayilavarapu, S., Hasturk, H., Serhan, C. N., and Van Dyke, T. E. (2011). Impaired phagocytosis in localized aggressive periodontitis: rescue by resolvin E1. PLoS ONE 6, e24422. doi:10.1371/journal.pone.0024422

Fredman, G., and Serhan, C. N. (2011). Specialized pro-resolving mediator targets for RvE1 and RvD1 in peripheral blood and mechanisms of resolution. Biochem. J. 437, 185-197.

Freire-de-Lima, C. G., Xiao, Y. Q., Gardai, S. J., Bratton, D. L., Schiemann, W. P., and Henson, P. M. (2006). Apoptotic cells, through transforming growth factor-beta, coordinately induce anti-inflammatory and suppress pro-inflammatory eicosanoid and NO synthesis in murine macrophages. J. Biol. Chem. 281, 38376-38384.

Gasser, O., and Schifferli, J. A. (2004). Activated polymorphonuclear neutrophils disseminate antiinflammatory microparticles by ectocytosis. Blood 104, 2543-2548.

Gewirtz, A. T., Neish, A. S., and Madara, J. L. (2002). Mechanisms of active intestinal inflammation and potential down-regulation via lipoxins. Adv. Exp. Med. Biol. 507, 229-236.

Gilroy, D. W., Colville-Nash, P. R., Willis, D., Chivers, J., Paul-Clark, M. J., and Willoughby, D. A. (1999). Inducible cyclooxygenase may have anti-inflammatory properties. Nat. Med. 5, 698-701.

GISSI-Prevenzione Investigators. (1999). Dietary supplementation with $n-3$ polyunsaturated fatty acids and vitamin $\mathrm{E}$ after myocardial infarction: results of the GISSIPrevenzione trial. Gruppo Italiano per lo Studio della Sopravvivenza nell'Infarto miocardico. Lancet 354, 447-455.

Godson, C., Mitchell, S., Harvey, K., Petasis, N. A., Hogg, N., and Brady, H. R. (2000). Cutting edge: lipoxins rapidly stimulate nonphlogistic phagocytosis of apoptotic neutrophils by monocytederived macrophages. J. Immunol. 164, 1663-1667.

Gonzalez-Periz, A., Horrillo, R., Ferre, N., Gronert, K., Dong, B., MoranSalvador, E., Titos, E., MartinezClemente, M., Lopez-Parra, M. Arroyo, V., and Claria, J. (2009). Obesity-induced insulin resistance and hepatic steatosis are alleviated by omega- 3 fatty acids: a role for resolvins and protectins. FASEB J. 23, 1946-1957.

Gordon, S. (2007). The macrophage: past, present and future. Eur. J. Immunol. 37(Suppl. 1), S9-S17.

Gronert, K., Gewirtz, A., Madara, J. L., and Serhan, C. N. (1998). Identification of a human enterocyte lipoxin A4 receptor that is regulated by interleukin (IL)-13 and interferon gamma and inhibits tumor necrosis factor alpha-induced IL-8 release. $J$. Exp. Med. 187, 1285-1294.

Gronert, K., Maheshwari, N., Khan, N., Hassan, I. R., Dunn, M., and Laniado Schwartzman, M. (2005). A role for the mouse 12/15-lipoxygenase pathway in promoting epithelial wound healing and host defense. J. Biol. Chem. 280, 15267-15278.

Gronert, K., Martinsson-Niskanen, T., Ravasi, S., Chiang, N., and Serhan, C. N. (2001). Selectivity of recombinant human leukotriene $\mathrm{D}(4)$, leukotriene $\mathrm{B}(4)$, and lipoxin $\mathrm{A}(4)$ receptors with aspirin-triggered 15 epi-LXA(4) and regulation of vascular and inflammatory responses. Am. J. Pathol. 158, 3-9.

Haas-Stapleton, E. J., Lu, Y., Hong, S., Arita, M., Favoreto, S., Nigam, S., Serhan, C. N., and Agabian, N. (2007). Candida albicans modulates host defense by biosynthesizing the pro-resolving mediator resolvin E1. PLoS ONE 2, e1316. doi:10.1371/journal.pone.0001316

Hasturk, H., Kantarci, A., GoguetSurmenian, E., Blackwood, A. Andry, C., Serhan, C. N., and Van Dyke, T. E. (2007). Resolvin E1 regulates inflammation at the cellular and tissue level and restores tissue homeostasis in vivo. J. Immunol. 179, 7021-7029.

Hasturk, H., Kantarci, A., Ohira, T., Arita, M., Ebrahimi, N., Chiang, N. Petasis, N. A., Levy, B. D., Serhan, C. N., and Van Dyke, T. E. (2006). $\mathrm{RvE} 1$ protects from local inflammation and osteoclast- mediated bone destruction in periodontitis. FASEB J. 20, 401-403.

Haworth, O., Cernadas, M., Yang, R., Serhan, C. N., and Levy, B. D. (2008). Resolvin E1 regulates interleukin 23, interferon-gamma and lipoxin A4 to promote the resolution of allergic airway inflammation. Nat. Immunol. 9, 873-879.

Hellmann, J., Tang, Y., Kosuri, M., Bhatnagar, A., and Spite, M. (2011) Resolvin D1 decreases adipose tissue macrophage accumulation and imiproves insulin sensitivity in obese-diabetic mice. FASEB J. 25 2399-2407.

Hong, S., Gronert, K., Devchand, P. R., Moussignac, R. L., and Serhan, C. N. (2003). Novel docosatrienes and 17S-resolvins generated from docosahexaenoic acid in murine brain, human blood, and glial cells. Autacoids in anti-inflammation. $J$. Biol. Chem. 278, 14677-14687.

Hong, S., Lu, Y., Yang, R., Gotlinger, K. H., Petasis, N. A., and Serhan, C. N. (2007). Resolvin D1, protectin D1, and related docosahexaenoic acidderived products: analysis via electrospray/low energy tandem mass spectrometry based on spectra and fragmentation mechanisms. J. Am. Soc. Mass Spectrom. 18, 128-144.

Hong, S., Porter, T. F., Lu, Y., Oh, S. F., Pillai, P. S., and Serhan, C. N. (2008). Resolvin E1 metabolome in local inactivation during inflammation-resolution. $J$. Immunol. 180, 3512-3519.

Honn, K. V., Grossi, I. M., Diglio, C. A., Wojtukiewicz, M., and Taylor, J. D. (1989). Enhanced tumor cell adhesion to the subendothelial matrix resulting from 12(S)-HETE-induced endothelial cell retraction. FASEB $J$. 3, 2285-2293

Huang, L., Wang, C.-F., Serhan, C. N., and Strichartz, G. (2011). Enduring prevention and transient reduction of post-operative pain by intrathecal resolvin D1. Pain 152, 557-565.
Iigo, M., Nakagawa, T., Ishikawa, C., Iwahori, Y., Asamoto, M., Yazawa, K., Araki, E., and Tsuda, H. (1997). Inhibitory effects of docosahexaenoic acid on colon carcinoma 26 metastasis to the lung. Br. J. Cancer 75, 650-655.

Iorio, M. V., and Croce, C. M. (2009). MicroRNAs in cancer: small molecules with a huge impact. J. Clin. Oncol. 27, 5848-5856.

Ishida, T., Yoshida, M., Arita, M., Nishitani, Y., Nishiumi, S., Masuda, A., Mizuno, S., Takagawa, T., Morita, Y., Kutsumi, H., Inokuchi, H., Serhan, C. N., Blumberg, R. S., and Azuma, T. (2010). Resolvin E1, an endogenous lipid derived from eicosapentaenoic acid, prevents dextran sulfate sodium-induced colitis. Inflamm. Bowel Dis. 16, 87-95.

Jin, Y., Arita, M., Zhang, Q., Saban, D. R., Chauhan, S. K., Chiang, N., Serhan, C. N., and Dana, R. (2009). Anti-angiogenesis effect of the novel anti-inflammatory and pro-resolving lipid mediators. Invest. Ophthalmol. Vis. Sci. 50, 4743-4752.

Karp, C. L., Flick, L. M., Park, K. W. Softic, S., Greer, T. M., Keledjian, R., Yang, R., Uddin, J., Guggino, W. B., Atabani, S. F., Belkaid, Y., Xu, Y., Whitsett, J. A., Accurso, F. J. Wills-Karp, M., and Petasis, N. A. (2004). Defective lipoxin-mediated anti-inflammatory activity in the cystic fibrosis airway. Nat. Immunol. 5, 388-392.

Kasuga, K., Yang, R., Porter, T. F., Agrawal, N., Petasis, N. A., Irimia, D. Toner, M., and Serhan, C. N. (2008). Rapid appearance of resolvin precursors in inflammatory exudates: novel mechanisms in resolution. $J$. Immunol. 181, 8677-8687.

Keyes, K. T., Ye, Y., Lin, Y., Zhang, C., Perez-Polo, J. R., Gjorstrup, P., and Birnbaum, Y. (2010). Resolvin E1 protects the rat heart against reperfusion injury. Am. J. Physiol. Heart Circ. Physiol. 299, H153-H164.

Krishnamoorthy, S., Recchiuti, A., Chiang, N., Fredman, G., and Serhan, C. N. (2012). Resolvin D1 receptor stereoselectivity and regulation of inflammation and pro-resolving microRNAs. Am. J. Pathol. 180, 2018-2027.

Krishnamoorthy, S., Recchiuti, A., Chiang, N., Yacoubian, S., Lee, C.-H., Yang, R., Petasis, N. A., and Serhan, C. N. (2010). Resolvin D1 binds human phagocytes with evidence for pro-resolving receptors. Proc. Natl. Acad. Sci. U.S.A. 107, 1660-1665.

Kunkel, S. L., Ogawa, H., Conran, P. B., Ward, P. A., and Zurier, R. B. (1981). Suppression of 
acute and chronic inflammation by orally administered prostaglandins. Arthritis Rheum. 24, 1151-1158.

Lawrence, T., Gilroy, D. W., ColvilleNash, P. R., and Willoughby, D. A. (2001). Possible new role for NFkappaB in the resolution of inflammation. Nat. Med. 7, 1291-1297.

Leitch, A. E., Lucas, C. D., Marwick, J. A., Duffin, R., Haslett, C., and Rossi, A. G. (2012). Cyclindependent kinases 7 and 9 specifically regulate neutrophil transcription and their inhibition drives apoptosis to promote resolution of inflammation. Cell Death Differ. doi: 10.1038/cdd.2012.80. [Epub ahead of print].

Levy, B. D., Clish, C. B., Schmidt, B., Gronert, K., and Serhan, C. N. (2001). Lipid mediator class switching during acute inflammation: signals in resolution. Nat. Immunol. 2, 612-619.

Levy, B. D., De Sanctis, G. T., Devchand, P. R., Kim, E., Ackerman, K., Schmidt, B. A., Szczeklik, W., Drazen, J. M., and Serhan, C. N. (2002). Multi-pronged inhibition of airway hyper-responsiveness and inflammation by lipoxin A(4). Nat. Med. 8, 1018-1023.

Levy, B. D., Kohli, P., Gotlinger, K., Haworth, O., Hong, S., Kazani, S., Israel, E., Haley, K. J., and Serhan, C. N. (2007). Protectin D1 is generated in asthma and dampens airway inflammation and hyperresponsiveness. J. Immunol. 178, 496-502.

Levy, B. D., Romano, M., Chapman, H. A., Reilly, J. J., Drazen, J., and Serhan, C. N. (1993). Human alveolar macrophages have 15-lipoxygenase and generate 15(S)-hydroxy-5,8,11cis-13-trans-eicosatetraenoic acid and lipoxins. J. Clin. Invest. 92, 1572-1579.

Levy, B. D., Zhang, Q. Y., Bonnans, C., Primo, V., Reilly, J. J., Perkins, D. L., Liang, Y., Arnaout, M. A., Nikolic, B., and Serhan, C. N. (2011). The endogenous proresolving mediators lipoxin $\mathrm{A}_{4}$ and resolvin E1 preserve organ function in allograft rejection. Prostaglandins Leukot. Essent. Fatty Acids 84, 43-50.

Li, N., He, J., Schwartz, C. E., Gjorstrup, P., and Bazan, H. E. P. (2010). Resolvin E1 improves tear production and decreases inflammation in a dry eye mouse model. J. Ocul. Pharmacol. Ther. 26, 431-439.

Lima-Garcia, J., Dutra, R., Da Silva, K., Motta, E., Campos, M., and Calixto, J. (2011). The precursor of resolvin D series and aspirin-triggered resolvin D1 display anti-hyperalgesic properties in adjuvant-induced arthritis in rats. Br. J. Pharmacol. 164, 278-293.

Lukiw, W. J., and Bazan, N. G. (2008). Docosahexaenoic acid and the aging brain. J. Nutr. 138, 2510-2514.

Maddox, J. F., Hachicha, M., Takano, T., Petasis, N. A., Fokin, V. V., and Serhan, C. N. (1997). Lipoxin A4 stable analogs are potent mimetics that stimulate human monocytes and THP-1 cells via a G-proteinlinked lipoxin A4 receptor. J. Biol. Chem. 272, 6972-6978.

Maderna, P., Cottell, D. C., Berlasconi, G., Petasis, N. A., Brady, H. R., and Godson, C. (2002). Lipoxins induce actin reorganization in monocytes and macrophages but not in neutrophils: differential involvement of rho GTPases. Am. J. Pathol. 160, 2275-2283.

Majno, G. (1991). The Healing Hand Man and Wound in the Ancient World. Cambridge: Harvard University Press.

Majno, G., and Joris, I. (1996). Cells, Tissues and Disease: Principles of General Pathology. Cambridge: Blackwell Science.

Marcheselli, V. L., Hong, S., Lukiw, W. J., Tian, X. H., Gronert, K., Musto, A., Hardy, M., Gimenez, J. M., Chiang, N., Serhan, C. N., and Bazan, N. G. (2003). Novel docosanoids inhibit brain ischemia-reperfusionmediated leukocyte infiltration and pro-inflammatory gene expression. J. Biol. Chem. 278, 43807-43817.

Marcheselli, V. L., Mukherjee, P. K., Arita, M., Hong, S., Antony, R., Sheets, K., Petasis, N., Serhan, C. N., and Bazan, N. G. (2010). Neuroprotectin D1/protectin D1 stereoselective and specific binding with human retinal pigment epithelial cells and neutrophils. Prostaglandins Leukot. Essent. Fatty Acids 82, 27-34.

Morris, T., Stables, M., Colville-Nash, P., Newson, J., Bellingan, G., De Souza, P. M., and Gilroy, D. W. (2010). Dichotomy in duration and severity of acute inflammatory responses in humans arising from differentially expressed proresolution pathways. Proc. Natl. Acad. Sci. U.S.A. 107, 8842-8847.

Morris, T., Stables, M., Hobbs, A., De Souza, P., Colville-Nash, P., Warner, T., Newson, J., Bellingan, G., and Gilroy, D. W. (2009). Effects of lowdose aspirin on acute inflammatory responses in humans. J. Immunol. 183, 2089-2096.

Mukherjee, P. K., Marcheselli, V. L., Serhan, C. N., and Bazan, N. G. (2004). Neuroprotectin D1: a docosahexaenoic acid-derived docosatriene protects human retinal pigment epithelial cells from oxidative stress. Proc. Natl. Acad. Sci. U.S.A. 101, 8491-8496.

Nathan, C., and Ding, A. (2010). Nonresolving inflammation. Cell 140 871-882.

Navarro-Xavier, R. A., Newson, J., Silveira, V. L. F., Farrow, S. N., Gilroy, D. W., and Bystrom, J. (2010). A new strategy for the identification of novel molecules with targeted proresolution of inflammation properties. J. Immunol. 184 1516-1525.

Nigam, S., Fiore, S., Luscinskas, F. W., and Serhan, C. N. (1990). Lipoxin A4 and lipoxin B4 stimulate the release but not the oxygenation of arachidonic acid in human neutrophils: dissociation between lipid remodeling and adhesion. J. Cell. Physiol. $143,512-523$.

Norling, L. V., Dalli, J., Flower, R. J., Serhan, C. N., and Perretti, M. (2012). Resolvin D1 limits polymorphonuclear leukocytes recruitment to inflammatory loci: receptor dependent actions. Arterioscler. Thromb. Vasc. Biol. 32, 1970-1978.

Norling, L.V., Spite, M., Yang, R., Flower, R. J., Perretti, M., and Serhan, C. N. (2011). Cutting edge: humanized nano-proresolving medicines mimic inflammation-resolution and enhance wound healing. J. Immunol. 186, 5543-5547.

Ogawa, S., Urabe, D., Yokokura, Y., Arai, H., Arita, M., and Inoue, M. (2009). Total synthesis and bioactivity of resolvin E2. Org. Lett. 11, 3602-3605.

Oh, S. F., Dona, M., Fredman, G., Krishnamoorthy, S., Irimia, D., and Serhan, C. N. (2012). Resolvin E2 formation and impact in inflammation resolution. J. Immunol. 188, 4527-4534.

Oh, S. F., Pillai, P. S., Recchiuti, A., Yang, R., and Serhan, C. N. (2011). Pro-resolving actions and stereoselective biosynthesis of $18 \mathrm{~S}$ E-series resolvins in human leukocytes and murine inflammation. J. Clin. Invest. $121,569-581$

Ohira, T., Arita, M., Omori, K., Recchiuti, A., Van Dyke, T. E., and Serhan, C. N. (2009). Resolvin E1 receptor activation signals phosphorylation and phagocytosis. J. Biol. Chem. 285, 3451-3461.

O'Neill, L. A., Sheedy, F. J., and McCoy, C. E. (2011). MicroRNAs: the finetuners of Toll-like receptor signalling. Nat. Rev. Immunol. 11, 163-175.

Papayianni, A., Serhan, C. N., Phillips, M. L., Rennke, H. G., and Brady,
H. R. (1995). Transcellular biosynthesis of lipoxin $\mathrm{A}_{4}$ during adhesion of platelets and neutrophils in experimental immune complex glomerulonephritis. Kidney Int. 47, 1295-1302.

Park, C. K., Lü, N., Xu, Z. Z., Liu, T., Serhan, C. N., and Ji, R. R. (2011). Resolving TRPV1 and TNF$(\alpha$-mediated spinal cord synaptic plasticity and inflammatory pain with neuroprotectin D1. J. Neurosci. 31, 15072-15085.

Perretti, M., Chiang, N., La, M., Fierro, I. M., Marullo, S., Getting, S. J., Solito, E., and Serhan, C. N. (2002). Endogenous lipid- and peptidederived anti-inflammatory pathways generated with glucocorticoid and aspirin treatment activate the lipoxin A4 receptor. Nat. Med. 8, 1296-1302.

Perretti, M., and Dalli, J. (2009). Exploiting the annexin Al pathway for the development of novel antiinflammatory therapeutics. $\mathrm{Br} . \mathrm{J}$. Pharmacol. 158, 936-946.

Psychogios, N., Hau, D. D., Peng, J., Guo, A. C., Mandal, R., Bouatra, S., Sinelnikov, I., Krishnamurthy, R., Eisner, R., Gautam, B., Young, N., Xia, J., Knox, C., Dong, E., Huang, P., Hollander, Z., Pedersen, T. L., Smith, S. R., Bamforth, F., Greiner, R., McManus, B., Newman, J. W., Goodfriend, T., and Wishart, D. S. (2011). The human serum metabolome. PLoS ONE 6, e16957. doi:10.1371/journal.pone.0016957

Radmark, O., Werz, O., Steinhilber, D., and Samuelsson, B. (2007). 5Lipoxygenase: regulation of expression and enzyme activity. Trends Biochem. Sci. 32, 332-341.

Rajasagi, N. K., Reddy, P. B. J., Suryawanshi, A., Mulik, S., Gjorstrup, P., and Rouse, B. T. (2011). Controlling herpes simplex virus-induced ocular inflammatory lesions with the lipid-derived mediator resolvin E1. J. Immunol. 186, 1735-1746.

Recchiuti, A., Krishnamoorthy, S., Fredman, G., Chiang, N., and Serhan, C. N. (2011). MicroRNAs in resolution of acute inflammation: identification of novel resolvin D1-miRNA circuits. FASEB J. 25 , 544-560.

Reville, K., Crean, J. K., Vivers, S., Dransfield, I., and Godson, C. (2006) Lipoxin A4 redistributes myosin IIA and Cdc42 in macrophages: implications for phagocytosis of apoptotic leukocytes. J. Immunol. 176, 1878-1888.

Romano, M. (2010). Lipoxin and aspirin-triggered lipoxins. ScientificWorldJournal 10, 1048-1064. 
Romano, M., and Serhan, C. N. (1992). Lipoxin generation by permeabilized human platelets. Biochemistry 31, 8269-8277.

Samuelsson, B. (1983). Leukotrienes: mediators of immediate hypersensitivity reactions and inflammation. Science 220, 568-575.

Samuelsson, B. (2012). Role of basic science in the development of new medicines: examples from the eicosanoid field. J. Biol. Chem. 287, 10070-10080.

Samuelsson, B., Dahlen, S. E., Lindgren, J. A., Rouzer, C. A., and Serhan, C. N. (1987). Leukotrienes and lipoxins: structures, biosynthesis, and biological effects. Science 237, 1171-1176.

Scalia, R., Gefen, J., Petasis, N. A., Serhan, C. N., and Lefer, A. M. (1997). Lipoxin A4 stable analogs inhibit leukocyte rolling and adherence in the rat mesenteric microvasculature: role of P-selectin. Proc. Natl. Acad. Sci. U.S.A. 94, 9967-9972.

Schwab, J. M., Chiang, N., Arita, M., and Serhan, C. N. (2007). Resolvin E1 and protectin D1 activate inflammation-resolution programmes. Nature 447, 869-874.

Serhan, C. N. (2004). A search for endogenous mechanisms of antiinflammation uncovers novel chemical mediators: missing links to resolution. Histochem. Cell Biol. 122, 305-321.

Serhan, C. N., Brain, S. D., Buckley, C. D., Gilroy, D. W., Haslett, C., O’Neill, L. A., Perretti, M., Rossi, A. G., and Wallace, J. L. (2007). Resolution of inflammation: state of the art, definitions and terms. FASEB J. 21, 325-332.

Serhan, C. N., and Chiang, N. (2008). Endogenous pro-resolving and antiinflammatory lipid mediators: a new pharmacologic genus. Br. J. Pharmacol. 153(Suppl. 1), S200-S215.

Serhan, C. N., Clish, C. B., Brannon, J., Colgan, S. P., Chiang, N., and Gronert, K. (2000a). Novel functional sets of lipid-derived mediators with antiinflammatory actions generated from omega-3 fatty acids via cyclooxygenase 2-nonsteroidal antiinflammatory drugs and transcellular processing. J. Exp. Med. 192, 1197-1204.

Serhan, C. N., Clish, C. B., Brannon, J., Colgan, S. P., Gronert, K., and Chiang, N. (2000b). Antimicroinflammatory lipid signals generated from dietary N-3 fatty acids via cyclooxygenase- 2 and transcellular processing: a novel mechanism for NSAID and N-3 PUFA therapeutic actions. J. Physiol. Pharmacol. 51, 643-654.
Serhan, C. N., Dalli, J., Karamnov, S., Choi, A., Park, C. K., Xu, Z. Z., Ji, R. R., Zhu, M., and Petasis, N. A. (2012). Macrophage pro-resolving mediator maresin 1 stimulates tissue regeneration and controls pain. FASEB J. 26, 1755-1765.

Serhan, C. N., Gotlinger, K., Hong, S., Lu, Y., Siegelman, J., Baer, T., Yang, R., Colgan, S. P., and Petasis, N. A. (2006). Anti-inflammatory actions of neuroprotectin D1/protectin D1 and its natural stereoisomers: assignments of dihydroxy-containing docosatrienes. J. Immunol. 176, 1848-1859.

Serhan, C. N. (Guest ed.). (2005). Lipoxins and aspirin-triggered lipoxins. Prostaglandins Leukot. Essent. Fatty Acids 73, 139-321. (special issue).

Serhan, C. N., Haeggstrom, J. Z., and Leslie, C. C. (1996). Lipid mediator networks in cell signaling: update and impact of cytokines. FASEB J. 10, 1147-1158.

Serhan, C. N., Hamberg, M., and Samuelsson, B. (1984a). Lipoxins: novel series of biologically active compounds formed from arachidonic acid in human leukocytes. Proc. Natl. Acad. Sci. U.S.A. 81, 5335-5339.

Serhan, C. N., Hamberg, M., and Samuelsson, B. (1984b). Trihydroxytetraenes: a novel series of compounds formed from arachidonic acid in human leukocytes. Biochem. Biophys. Res. Commun. 118, 943-949.

Serhan, C. N., Hong, S., Gronert, K., Colgan, S. P., Devchand, P. R., Mirick, G., and Moussignac, R.-L. (2002). Resolvins: a family of bioactive products of omega3 fatty acid transformation circuits initiated by aspirin treatment that counter proinflammation signals. J. Exp. Med. 196, 1025-1037.

Serhan, C. N., Jain, A., Marleau, S., Clish, C., Kantarci, A., Behbehani, B., Colgan, S. P., Stahl, G. L., Merched, A., Petasis, N. A., Chan, L., and Van Dyke, T. E. (2003). Reduced inflammation and tissue damage in transgenic rabbits overexpressing 15-lipoxygenase and endogenous anti-inflammatory lipid mediators. J. Immunol. 171, 6856-6865.

Serhan, C. N., Maddox, J. F., Petasis, N. A., Akritopoulou-Zanze, I., Papayianni, A., Brady, H. R., Colgan, S. P., and Madara, J. L. (1995). Design of lipoxin $\mathrm{A}_{4}$ stable analogs that block transmigration and adhesion of human neutrophils. Biochemistry 34, 14609-14615.
Serhan, C. N., and Petasis, N. A. (2011). Resolvins and protectins in inflammation-resolution. Chem. Rev. 111, 5922-5943.

Serhan, C. N., and Savill, J. (2005). Resolution of inflammation: the beginning programs the end. Nat. Immunol. 6, 1191-1197.

Serhan, C. N., and Sheppard, K. A. (1990). Lipoxin formation during human neutrophil-platelet interactions. Evidence for the transformation of leukotriene A4 by platelet 12 lipoxygenase in vitro. J. Clin. Invest. 85, 772-780.

Serhan, C. N., Yang, R., Martinod, K. Kasuga, K., Pillai, P. S., Porter, T. F., Oh, S. F., and Spite, M. (2009). Maresins: novel macrophage mediators with potent antiinflammatory and proresolving actions. J. Exp. Med. 206, 15-23.

Sheedy, F. J., and O'Neill, L. A. J. (2008). Adding fuel to fire: microRNAs as a new class of mediators of inflammation. Ann. Rheum. Dis. 67(Suppl. 3), 50-55.

Sheedy, F. J., Palsson-McDermott, E., Hennessy, E. J., Martin, C., O'Leary, J. J., Ruan, Q., Johnson, D. S., Chen, Y., and O'Neill, L. A. (2010). Negative regulation of TLR4 via targeting of the proinflammatory tumor suppressor PDCD4 by the microRNA miR-21. Nat. Immunol. 11, 141-147.

Simiele, F., Recchiuti, A., Mattoscio, D. De Luca, A., Cianci, E., Franchi, S., Gatta, V., Parolari, A., Werba, J. P., Camera, M., Favoloro, B., and Romano, M. (2012). Transcriptional regulation of the human FPR2/ALX gene: evidence of a heritable genetic variant that impairs promoter activity. FASEB J. 26, 1323-1333.

Spite, M., Norling, L. V., Summers, L., Yang, R., Cooper, D., Petasis, N. A., Flower, R. J., Perretti, M., and Serhan, C. N. (2009a). Resolvin D2 is a potent regulator of leukocytes and controls microbial sepsis. Nature 461, 1287-1291.

Spite, M., Summers, L., Porter, T. F., Srivastava, S., Bhatnagar, A., and Serhan, C. N. (2009b). Resolvin D1 controls inflammation initiated by glutathione-lipid conjugates formed during oxidative stress. $\mathrm{Br}$. J. Pharmacol. 158, 1062-1073.

Spite, M., and Serhan, C. N. (2011). Lipid signatures of unstable atheromas: fossils or a step toward personalized lipidomicsmetabolomics? Circ. Cardiovasc. Genet. 4, 215-217.

Stein, C., Clark, J. D., Oh, U., Vasko, M. R., Wilcox, G. L., Overland, A.
C., Vanderah, T. W., and Spencer, R. H. (2009). Peripheral mechanisms of pain and analgesia. Brain Res. Rev. 60, 90-113.

Sun, Y.-P., Oh, S. F., Uddin, J., Yang, R., Gotlinger, K., Campbell, E., Colgan, S. P., Petasis, N. A., and Serhan, C. N. (2007). Resolvin $\mathrm{D} 1$ and its aspirin-triggered 17R epimer. Stereochemical assignments, anti-inflammatory properties, and enzymatic inactivation. J. Biol. Chem. 282, 9323-9334.

Svensson, C. I., Zattoni, M., and Serhan, C. N. (2007). Lipoxins and aspirintriggered lipoxin inhibit inflammatory pain processing. J. Exp. Med. 204, 245-252.

Takano, T., Clish, C. B., Gronert, K., Petasis, N., and Serhan, C. N. (1998). Neutrophil-mediated changes in vascular permeability are inhibited by topical application of aspirintriggered 15-epi-lipoxin A4 and novel lipoxin B4 stable analogues. J. Clin. Invest. 101, 819-826.

Takano, T., Fiore, S., Maddox, J. F., Brady, H. R., Petasis, N. A., and Serhan, C. N. (1997). Aspirin-triggered 15-epilipoxin A4 (LXA4) and LXA4 stable analogues are potent inhibitors of acute inflammation: evidence for anti-inflammatory receptors. J. Exp. Med. 185, 1693-1704.

Titos, E., Rius, B., González-Périz, A., López-Vicario, C., Morán-Salvador, E., Martínez-Clemente, M., Arroyo, V., and Clária, J. (2011). Resolvin D1 and its precursor docosahexaenoic acid promote resolution of adipose tissue inflammation by elicitying macrophage polarization toward a pro-resolving phenotype. $J$. Immunol. 187, 5408-5418.

Tjonahen, E., Oh, S. F., Siegelman, J., Elangovan, S., Percarpio, K. B., Hong, S., Arita, M., and Serhan, C. N. (2006). Resolvin E2: identification and anti-inflammatory actions: pivotal role of human 5-lipoxygenase in resolvin E series biosynthesis. Chem. Biol. 13, 1193-1202.

Tobin, D. M., Roca, F. J., Oh, S. F., McFarland, R., Vickery, T. W., Ray, J. P., Ko, D. C., Zou, Y., Bang, N. D., Chau, T. T., Vary, J. C., Hawn, T. R., Dunstan, S. J., Farrar, J. J., Thwaites, G. E., King, M. C., Serhan, C. N., and Ramakrishnan, L. (2012). Host genotype-specific therapies can optimize the inflammatory response to mycobacterial infections. Cell 148 , 434-446.

von Euler, U. S. (1973). The First Heymans Memorial Lecture, Ghent, March 24, 1972. Some aspects of the actions of prostaglandins. Arch. Int. 
Pharmacodyn. Ther. (Suppl), Apr, 295-307.

Wang, B., Gong, X., Wan, J. Y., Zhang, L., Zhang, Z., Li, H. Z., and Min, S. (2011). Resolvin D1 protects mice from LPS-induced acute lung injury. Pulm. Pharmacol. Ther. 24, 434-441.

Winyard, P. G., and Willoughby, D. A. (eds). (2003). Inflammation Protocols. Totowa, NJ: Humana.

Wittamer, V., Franssen, J. D., Vulcano, M., Mirjolet, J. F., Le Poul, E., Migeotte, I., Brezillon, S., Tyldesley, R., Blanpain, C., Detheux, M., Mantovani, A., Sozzani, S., Vassart, G., Parmentier, M., and Communi, D. (2003). Specific recruitment of antigen-presenting cells by chemerin, a novel processed ligand from human inflammatory fluids. J. Exp. Med. 198, 977-985.
Xu, Z.-Z., Zhang, L., Liu, T., Park, J.-Y., Berta, T., Yang, R., Serhan, C. N., and Ji, R.-R. (2010). Resolvins RvE1 and RvD1 attenuate inflammatory pain via central and peripheral actions. Nat. Med. 16, 592-597.

Ye, R. D., Boulay, F., Wang, J. M., Dahlgren, C., Gerard, C., Parmentier, M., Serhan, C. N., and Murphy, P. M. (2009). International Union of Basic and Clinical Pharmacology. LXXIII. Nomenclature for the formyl peptide receptor (FPR) family. Pharmacol. Rev. 61, 119-161.

Zhao, Y., Calon, F., Julien, C., Winkler, J. W., Petasis, N. A., Lukiw, W. J., and Bazan, N. G. (2011). Docosahexaenoic acid-derived neuroprotectin D1 induces neuronal survival via secretase- and PPARgamma-mediated mechanisms in Alzheimer's disease models. PLoS ONE 6, el5816. doi:10.1371/journal.pone.0015816

Zhou, M., Chen, B., Sun, H., Deng, Z., Andersson, R., and Zhang, Q. (2011). The protective effects of lipoxin A4 during the early phase of severe aute pancreatitis in rats. Scand. J. Gastroenterol. 46, 211-219.

Conflict of Interest Statement: Charles N. Serhan is an inventor on patents [resolvins] assigned to $\mathrm{BWH}$ and licensed to Resolvyx Pharmaceuticals. Charles N. Serhan is a scientific founder of Resolvyx Pharmaceuticals and owns equity in the company. Charles N. Serhan's interests were reviewed and are managed by the Brigham and Women's Hospital and Partners HealthCare in accordance with their conflict of interest policies. Antonio Recchiuti declares no conflict of interest.
Received: 19 July 2012; paper pending published: 08 August 2012; accepted: 07 September 2012; published online: 22 October 2012.

Citation: Recchiuti A and Serhan CN (2012) Pro-resolving lipid mediators $(S P M s)$ and their actions in regulating miRNA in novel resolution circuits in inflammation. Front. Immun. 3:298. doi: 10.3389/fimmu. 2012.00298

This article was submitted to Frontiers in Inflammation, a specialty of Frontiers in Immunology.

Copyright $\odot 2012$ Recchiuti and Serhan. This is an open-access article distributed under the terms of the Creative Commons Attribution License, which permits use, distribution and reproduction in other forums, provided the original authors and source are credited and subject to any copyright notices concerning any third-party graphics etc. 